\title{
Laminin $\beta 2$ Chain Regulates Retinal Progenitor Cell Mitotic Spindle Orientation via Dystroglycan
}

\author{
Dmitri Serjanov, Galina Bachay, Dale D. Hunter, and William J. Brunken \\ Department of Ophthalmology, Upstate Medical University, Syracuse, New York 13210
}

Vertebrate retinal development follows a pattern during which retinal progenitor cells (RPCs) give rise to all retinal cell types in a highly conserved temporal sequence. RPC proliferation and cell cycle exit are tightly coordinated to ensure proper and timely production of each of the retinal cell types. Extracellular matrix (ECM) plays an important role in eye development, influencing RPC proliferation and differentiation. In this study, we demonstrate that laminins, key ECM components, in the inner limiting membrane, control mitotic spindle orientation by providing environmental cues to the RPCs. In vivo deletion of laminin $\beta 2$ in mice of both sexes results in a loss RPC basal processes and contact with the ECM, leading to a shift of the mitotic spindle pole orientation toward asymmetric cell divisions. This leads to decreased proliferation and premature RPC pool depletion, resulting in overproduction of rod photoreceptors at the expense of bipolar cells and Müller glia. Moreover, we show that deletion of laminin $\beta 2$ leads to disruption and mislocalization of its receptors: dystroglycan and $\beta 1$-integrin. Addition of exogenous $\beta 2$-containing laminins to laminin $\beta 2$-deficient retinal explants stabilizes the RPC basal processes and directs their mitotic spindle orientation toward symmetric divisions, leading to increased RPC proliferation, as well as restores proper receptor localization at the retinal surface. Finally, functional blocking of dystroglycan in wild-type retinal explants phenocopies laminin $\beta 2$ ablation. Our data suggest that dystroglycan-mediated signaling between RPCs and the ECM is of key importance in controlling critical developmental events during retinogenesis.

Key words: extracellular matrix; mitotic spindle; neurogenesis; retinal development

Significance Statement

The mechanisms governing retinogenesis are subject to both intrinsic and extrinsic signaling cues. Although the role of intrinsic signaling has been the subject of many studies, our understanding of the role of the microenvironment in retinal development remains unclear. Using a combination of in vivo and ex vivo approaches, we demonstrate that laminins, key extracellular matrix components, provide signaling cues that control retinal progenitor cell attachment to the basement membrane, mitotic axis, proliferation, and fate adoption. Moreover, we identify, for the first time, dystroglycan as the receptor responsible for directing retinal progenitor cell mitotic spindle orientation. Our data suggest a mechanism where dystroglycan-mediated signaling between the cell and the extracellular matrix controls the proliferative potential of progenitors in the developing CNS.

\section{Introduction}

The vertebrate retina is a highly structured component of the CNS populated by seven resident cell types. These include rod

\footnotetext{
Received Feb. 27, 2018; revised May 10, 2018; accepted May 18, 2018.

Author contributions:D.S. wrote the first draft of the paper; D.S., D.D.H., and W.J.B. edited the paper; D.S., D.D.H., and W.J.B. designed research; D.S. and G.B. performed research; G.B. and W.J.B. contributed unpublished reagents/ analytic tools; D.S., D.D.H., and W.J.B. analyzed data; D.S. and W.J.B. wrote the paper.

This work was supported by National Institutes of Health Grant 5R01 EY12676-15 to W.J.B. and Research to Prevent Blindness Unrestricted Grant to Department of Ophthalmology, Upstate Medical University. We thank Dr. Heidi Hehnly (Upstate Medical University) and Dr. Saptarshi Biswas (Columbia University) for helpful discussions and feedback; Dr. Kevin Campbell (HHMI, University of lowa), Dr. Dominique Mornet (Université de Montpellier), and Dr. Cheryl Craft (University of California-Los Angeles) for kindly providing the antibodies that were crucial for this work; and Dr. Reyna Martinez-De Luna (Upstate Medical University) and Jared Watters (Upstate Medical University) for critical reading and feedback on the manuscript.

The authors declare no competing financial interests.

Correspondence should be addressed to Dr. William J. Brunken, Department of Ophthalmology, Upstate Medical University, 750 East Adams Street, Syracuse, NY 13210. E-mail: brunkenw@upstate.edu.
}

and cone photoreceptors as well as ganglion, horizontal, amacrine, bipolar cells, and Müller glia. In vertebrates, these cell types arise from a single population of multipotent retinal progenitor cells (RPCs) in a conserved order. Ganglion cells, horizontal cells, amacrine cells, and cones are born first, followed by rods, then bipolar cells and, finally, Müller glia (Young, 1985; Turner and Cepko, 1987; Holt et al., 1988; Turner et al., 1990). This sequence is dictated by gradual modulation of RPC competence and proliferation. With each cell division, a subset of RPCs shift from proliferative, toward a fate-restricted state, leading to cell cycle exit and adoption of neural or glial fate (Cepko et al., 1996).

The mechanisms governing the balance between RPC cell cycle exit and reentry are subject to both intrinsic and extrinsic cues. 
While transcription factors and cell cycle regulators have been shown to play critical roles, RPCs are exposed to a continuously changing environment of extracellular signals throughout retinogenesis (Agathocleous and Harris, 2009). One set of extracellular signals is provided by the extracellular matrix (ECM), including the basement membrane (BM). BMs are sheet-like ECMs that influence cell orientation, proliferation, differentiation, apoptosis, migration, adhesion, and cytoskeletal organization (Yurchenco, 2011). BM disruptions lead to diseases and developmental abnormalities, including in the eye (Varshney et al., 2015).

One of the basic components of the BM assembly is the laminin family of proteins, which function as heterotrimers composed of $\alpha, \beta$, and $\gamma$ subunits. Laminin mutations cause severe developmental abnormalities in human and mouse (for review, see Yao, 2017). Expressed as early as 4-cell stage, laminins are indispensable for BM assembly. Embryos lacking $\alpha-1, \beta-1$, or $\gamma-1$ laminins fail to compose Reichert's membrane and die shortly after implantation (Smyth et al., 1999; Miner et al., 2004). The importance of BM signaling is further revealed by studies on disruptions of laminin receptors, including dystroglycan (DG) and $\beta 1$-integrin. Specifically in the retina, disruption of DG and $\beta 1$-integrin leads to profound retinogenesis defects ( $\mathrm{Li}$ and Sakaguchi, 2004; Lunardi et al., 2006; Clements et al., 2017).

In addition to molecular signaling, the orientation of the plane of cytokinesis plays an important role in cell fate determination. Earlier studies noted that vertical divisions of the radial glia $(R G)$ in the developing cortex correlate with daughter cells assuming different fates (McConnell, 1995). Early in development, while the neural progenitor pool is expanding, RG divisions are strictly horizontal (Fish et al., 2006; Yingling et al., 2008), gradually shifting to vertically oriented divisions during neurogenic stages of development (Haydar et al., 2003). These studies suggest a model where progenitor cells dividing horizontally produce daughter cells of the same fate, whereas those dividing in an oblique fashion produce daughter cells of different fates: apical daughter cells stay proliferative, whereas basal daughter cells differentiate.

Using a combination of in vivo and ex vivo approaches, we investigated whether $\beta 2$-containing laminins provide epigenetic cues that govern the direction of RPC cytokinesis and fate choices. Here, we show that deletion of laminin $\beta 2$ results in retraction of RPC basal processes (BPs), leading to loss of contact between RPCs and the inner limiting membrane (ILM), which in turn increases the incidence of asymmetric cell divisions, and finally, premature cell cycle exit. As a result, RPC fate shifts toward rod photoreceptor production at the expense of bipolar cells and Müller glia. Addition of $\beta 2$-containing laminin-521 rescued RPC BP stability, mitotic axis, and proliferation. We also, for the first time, identify DG as the receptor responsible for directing RPC mitotic spindle orientation. Our data suggest a mechanism in which contact with the BM is of key importance in modulating RPC proliferation and fate choice.

\section{Materials and Methods}

Antibodies. Antibodies include the following: Centrin (Millipore, catalog \#04-1624 RRID:AB_10563501), phospho-histone H3 (pSer28) (SigmaAldrich, catalog \#H9908 RRID:AB_260096), Chx10 (Abcam, catalog \#ab16141 RRID:AB_302278), Sox9 (Millipore, catalog \#AB5535 RRID: AB_2239761), phospho-vimentin (Ser55) (MBL, catalog \#D076-3 RRID: AB_592963), syntaxin (Sigma-Aldrich, catalog \#S0664 RRID:AB_477483), $\alpha$-DG (Millipore, catalog \#05-298 RRID:AB_309674), $\beta$-1 integrin (Millipore, catalog \#MAB1997 RRID:AB_2128202), calbindin D28k (Synap- tic Systems, catalog \#214 005 RRID:AB_2619902), Olig2 (Millipore, catalog \#AB9610 RRID:AB_570666), cone arrestin (Nikonov et al., 2008) (Cheryl Craft, University of California-Los Angeles, mCAR-LUMIj), $\beta$-DG (Dominique Mornet, Université de Montpellier, JAF), $\alpha$-DG blocking antibody (Ervasti et al., 1990; Ervasti and Campbell, 1991) (Kevin Campbell, HHMI, University of Iowa, IIH6), $\beta$-1 integrin blocking antibody (BD Biosciences, catalog \#553715 RRID:AB_395001), IgM isotype control from murine myeloma (Sigma-Aldrich, catalog \#M5909 RRID:AB_1163655), and rat IgG2ak (BD Biosciences, catalog \#559073 RRID:AB_479682).

Chemicals, peptides, and recombinant proteins. Chemicals, peptides, and recombinant proteins include the following: 5-ethynyl-2-deoxyuridine (EdU) (Invitrogen, catalog \#C10337), Hoechst (Invitrogen, catalog \#H3570), laminin-521 (BioLamina, catalog \#LN521-3), laminin511 (BioLamina, catalog \#LN511-3), and donkey serum (Sigma-Aldrich, catalog \#D9663).

Experimental organisms. Experimental organisms include the following: C57BL/6J mice (The Jackson Laboratory, RRID:IMSR_JAX:000664) and Lamb2 ${ }^{-1-}$ mice (Noakes et al., 1995).

Software. Software includes the following: Volocity 3D Image Analysis Software (PerkinElmer, RRID:SCR_002668) and Prism (GraphPad, RRID:SCR_002798).

Experimental model. Deletion of the Lamb2 gene and production of the Lamb2 $2^{-1-}$ mice have been previously described (Noakes et al., 1995). $\mathrm{Lamb2}^{-1-}$ animals have been backcrossed to C57BL/6J over nine generations. The day of the vaginal plug was considered embryonic day (E) 0.5 . Animals were maintained as heterozygotes. All animal procedures were performed in accordance with the Institutional Committee (Institutional Animal Care and Use Committee) and the Institutional Biosafety Committee.

Immunostaining. The following antibodies were used: mouse antiCentrin (1:1000, Millipore, 04-1624), rat anti-phospho histone H3 (1: 3000, Sigma-Aldrich, H9908), sheep anti-Chx10 (1:300, Abcam, ab16141), rabbit anti-Sox9 (1:300, Millipore, AB5535), mouse antiphospho-vimentin (1:300, MBL, D076-3), rabbit anti-Olig2 (1:300, Millipore, AB9610), mouse anti-syntaxin (1:500, Sigma-Aldrich, S0664), rabbit anti-cone arrestin, mCAR-LUMIj $(1: 10,000)$, previously described (Nikonov et al., 2008) and a kind gift from gift from Cheryl Craft (University of California-Los Angeles), mouse anti- $\alpha$-DG (1:50, Millipore, 05-298), rabbit anti- $\beta$-DG (1:300, JAF), a kind gift from Dominique Mornet (Université de Montpellier), rat anti- $\beta 1$-integrin (1:300, Millipore, MAB1997), and guinea pig anti-calbindin (1:600, Synaptic Systems, 214 005). Donkey anti-mouse 488 and 594, donkey anti-rabbit 594 and 647, donkey anti-rat 594, donkey anti-guinea pig 488, and donkey anti-sheep 488 secondary antibodies were used (Invitrogen); Hoechst staining was performed (1:100,000, Invitrogen, H3570).

Retinal preparations. For flat-mount retinal preparations, eyes were enucleated and dissected without fixation, separating the neural retina and the retinal pigment epithelium (RPE). Retinas were then flatmounted on cover glasses and gently lowered into $4 \%$ PFA in PBS $(\mathrm{NaCl}$ $\left.8 \mathrm{~g} / \mathrm{L}, \mathrm{Na}_{2} \mathrm{HPO}_{4} 1.44 \mathrm{~g} / \mathrm{L}, \mathrm{KCl} 0.2 \mathrm{~g} / \mathrm{L}, \mathrm{KH}_{2} \mathrm{PO}_{4} 0.24 \mathrm{~g} / \mathrm{L}, \mathrm{pH} 7.2\right)$ at $4^{\circ} \mathrm{C}$ for $30-60 \mathrm{~s}$ allowing retina to detach from the glass while leaving residual RPE cells attached to the glass. Following washing in PBS, retinas were treated with absolute methanol at $4^{\circ} \mathrm{C}$ for $5 \mathrm{~min}$ and slowly rehydrated by incubating with gradually decreasing concentrations of methanol in PBS over the course of $3 \mathrm{~h}$. After washing in PBS, retinas were incubated overnight at $4^{\circ} \mathrm{C}$ in blocking solution ( $10 \%$ donkey serum, $0.01 \%$ Tween 20, PBS). Next, retinas were incubated with primary antibodies in $300 \mu \mathrm{l}$ blocking solution at $4^{\circ} \mathrm{C}$ for $24 \mathrm{~h}$, washed, and incubated with secondary antibodies in blocking solution overnight. Following washing, tissues were mounted in ProLong Gold Antifade Reagent (Invitrogen, P36930). Only peripheral retinal regions were imaged and analyzed. Radial sections were prepared by fixing the eyes in $4 \%$ PFA for $10 \mathrm{~min}$, cryoprotecting in $30 \%$ sucrose, and mounted in OCT embedding medium. The $16 \mu \mathrm{m}$ sections were collected on microscope slides with a cryostat. Sections were washed in PBS and then blocked for $30 \mathrm{~min}$ at room temperature in 5\% donkey serum in PBS with $0.3 \%$ Triton X-100. Following washing in PBS, sections were incubated with primary antibodies overnight at $4^{\circ} \mathrm{C}$ in $5 \%$ donkey serum in PBS with $0.01 \%$ Triton X-100 $(25 \mu \mathrm{l}$ 


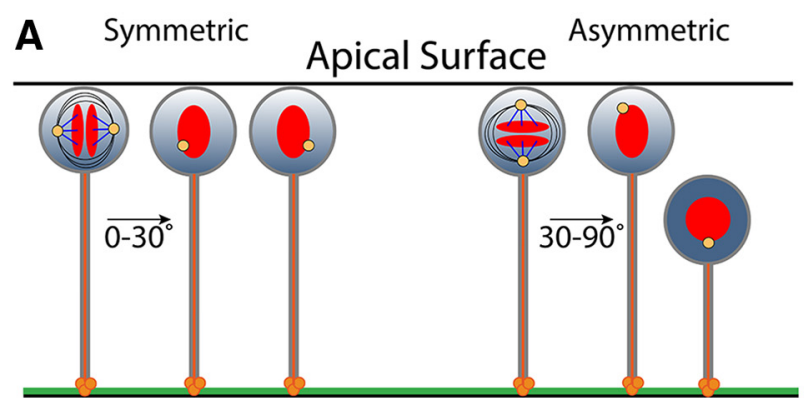

o-Centrosome Basal Surface (ILM)

\section{B}

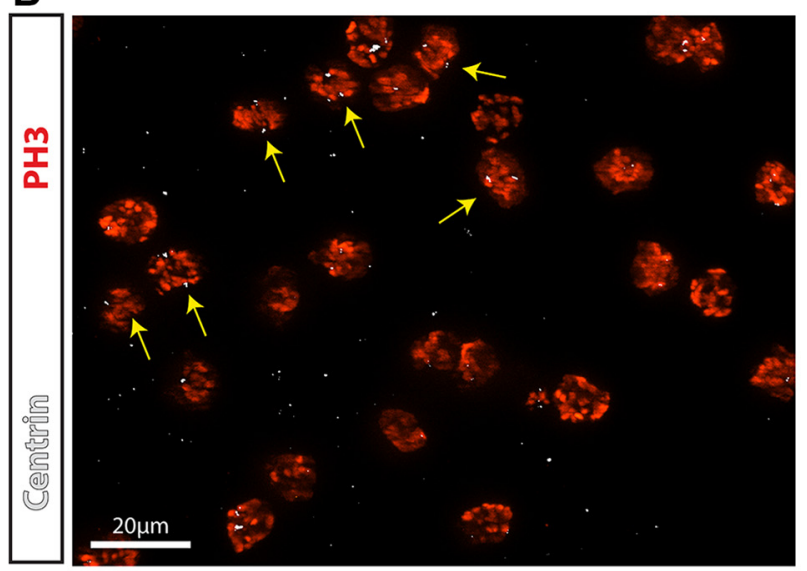

C
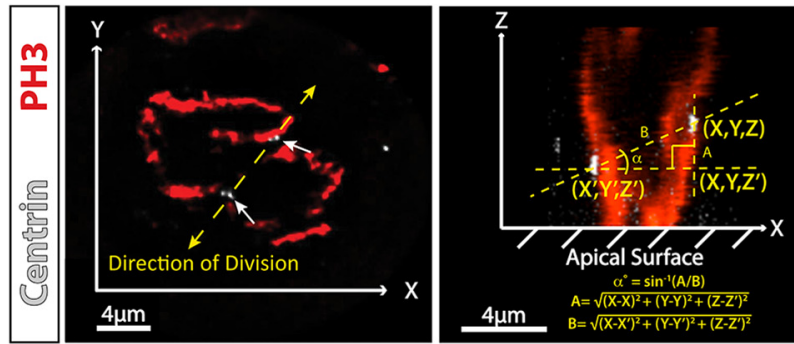

D

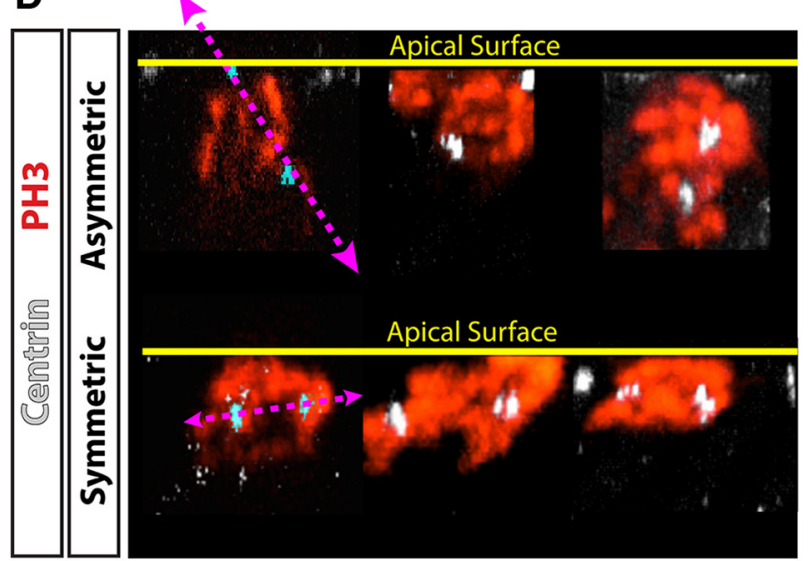

E

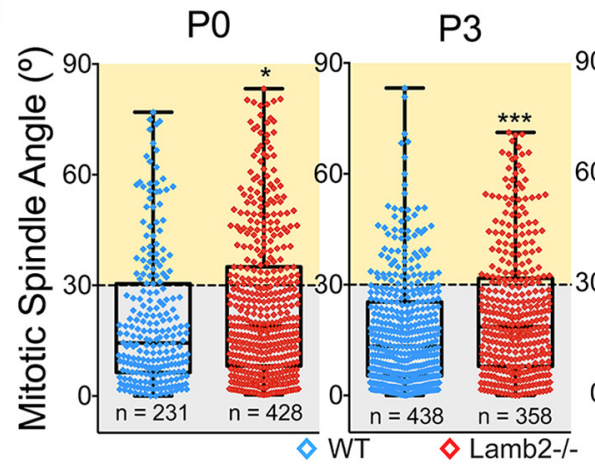

P5

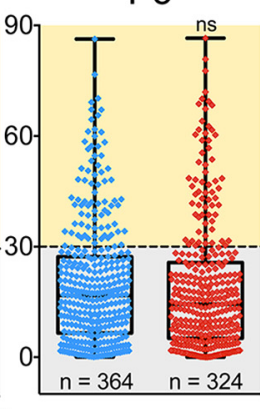

F
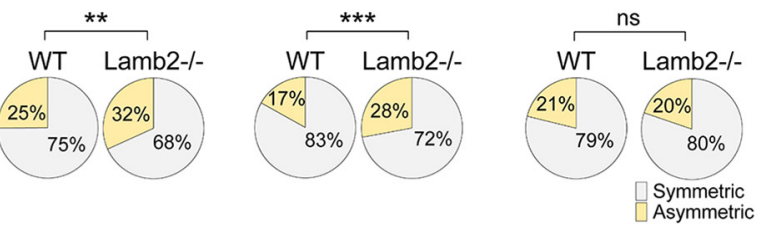

\section{Ex Vivo}

G

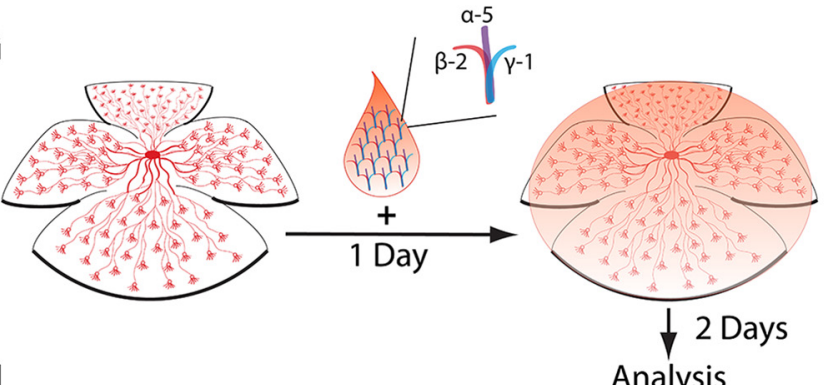

H

ns

Analysis
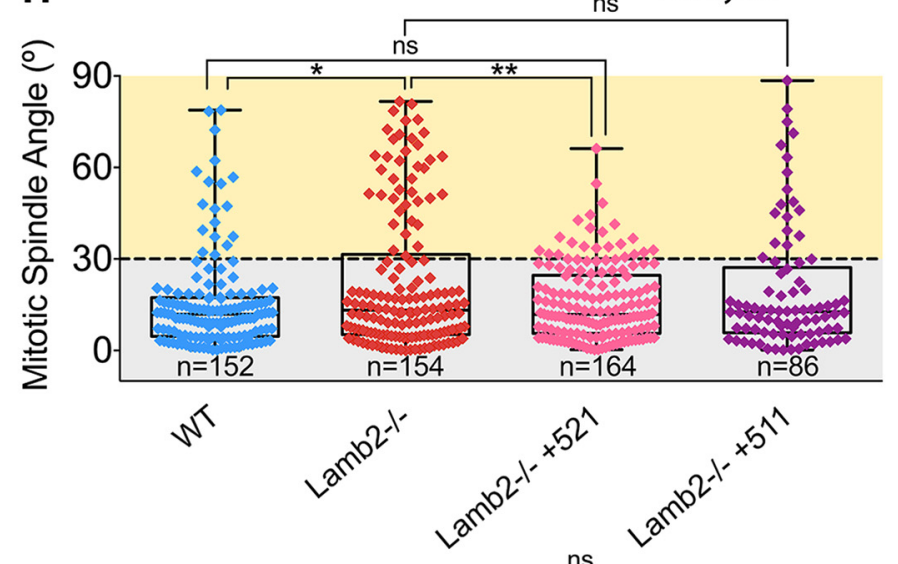

I
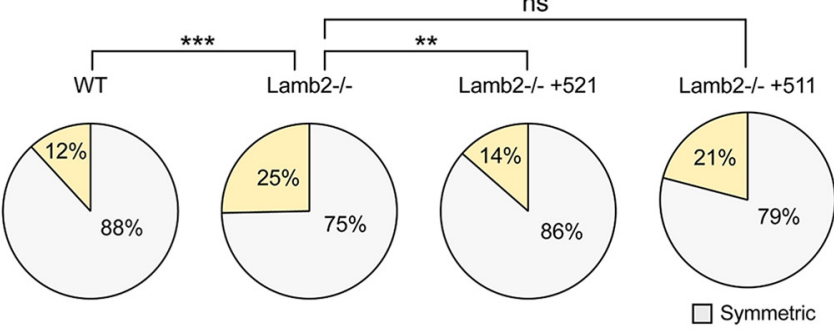

$\square$ Symmetric

Figure 1. RPC mitotic spindle orientation is laminin $\beta 2$-dependent. $\boldsymbol{A}$, Symmetric and asymmetric cell division model. Divisions occurring parallel to the apical surface result in assumption of the same fate by both daughters due to even distribution of intracellular fate determining factors (shown as white-blue gradient) as well as inheritance of apical domain and BPs. In early stages, such divisions result in expansion of the progenitor pool, producing two proliferative RPCs. Later in development, such divisions produce two postmitotic daughters. These divisions are referred to as symmetric and are typically considered to include divisions at an angle of $\leq 30^{\circ}$ relative to the surface. Divisions occurring at an angle $>30^{\circ}$ are typically referred to as oblique or asymmetric and are more likely to result in different fate adoption by the daughters. The apical daughter remains proliferative, whereas the basal daughter leaves cell cycle as a result of asymmetric inheritance of fate determining factors. B, Optical section of the apical surface of a retinal flat-mount stained for PH3 (red) to mark mitotic cells, and centrin (white) to mark centrosomes. Arrows indicate RPCs in prometa/metaphase. C, Left, Optical section of a single mitotic RPC in metaphase at the apical surface of a retinal flat-mount. Arrows indicate centrosomes. (Figure legend continues.) 
per section). Following washing in PBS, sections were incubated with secondary antibodies for $4 \mathrm{~h}$ at room temperature. Following incubation with secondary antibodies, sections were washed and mounted in Vectashield mounting medium (Vector Laboratories, H-1000) and imaged. To ensure that comparable regions of the retina were analyzed, all sections used were oriented nasal-temporally and traversed the optic nerve.

Fate tracking. EdU in sterile saline was administered as intraperitoneal injections at the concentration of $100 \mathrm{mg} / \mathrm{kg}$ body weight. Mice were injected once at P0, P3, or P5. At P15, eyes were collected, prepared, and sectioned as described above. EdU was detected per the manufacturer's instructions and used in combination with anti-Chx10 and anti-Sox9 antibodies. Percentages of RPCs that became rod photoreceptors were calculated as percentage of bright $\mathrm{EdU}^{+}$cells present in the outer nuclear layer (ONL). Similarly, RPCs that became bipolar cells or Müller glia were determined by percentage of bright $\mathrm{EdU}^{+} \mathrm{Chx} 0^{+}$, or bright $\mathrm{EdU}{ }^{+}$ Sox $9^{+}$cells, respectively.

Organotypic retinal cultures. Organotypic retinal cultures with RPE intact were prepared as described previously (Stoppini et al., 1991; Pinzón-Duarte et al., 2000) with modifications. Briefly, P0 eyes were enucleated and dissected in sterile HBSS. The sclera was removed using a pair of forceps. Cornea was removed using microdissection scissors taking care to leave the iris and ciliary body intact. Four radial cuts were made to flatten the sample, which was then transferred, ganglion cell side up, to the upper compartment of a Costar Transwell Permeable Support (Corning; 3401) containing enough medium to keep the tissue moist without covering it completely $(300-350 \mu \mathrm{l})$, with $650 \mu \mathrm{l}$ in the lower compartment. Culture medium consisted of the following: 1:1 DMEM/ F12 with hydrocortisone (20 nM), insulin $(5 \mathrm{mg} / \mathrm{ml})$, progesterone $(20$ $\mathrm{nM})$, putrescine $(100 \mathrm{mM})$, selenium $(20 \mathrm{nM})$, taurine $(3 \mathrm{~mm})$, transferrin $(1 \mathrm{mg} / \mathrm{ml}), 5 \% \mathrm{FCS}$, and $5 \%$ horse serum. No antifungal or antibiotic agents were used. Cultures were kept in an incubator with $5 \% \mathrm{CO}_{2}$ at $37^{\circ} \mathrm{C} ; 400 \mu \mathrm{l}$ of medium was changed after the first day in culture.

Ex vivo rescue and receptor blocking experiments. For rescue studies, following medium change, $10 \mu \mathrm{l}$ medium containing 50 pm laminin-521 was placed on the retinal surface. Medium containing no laminin was used as negative control. For receptor blocking studies, following medium change, $10 \mu \mathrm{l}$ medium containing $1 \mathrm{~nm} \alpha$-DG blocking antibody or $500 \mathrm{pm} \beta 1$-integrin blocking antibody or both was placed on the retinal surface. Nonspecific IgM and IgG2ak were used as isotype controls, respectively. After 3 DIV, cultures were fixed for flat-mounts or cryosections as described above. Monoclonal blocking antibody to $\alpha$-DG (IIH6) has been previously described (Ervasti et al., 1990; Ervasti and Campbell, 1991) and was a kind gift from Dr. Kevin Campbell (HHMI, University of Iowa). Rat $\beta 1$-integrin blocking antibody (9EG7, BD Biosciences Pharmingen, 553715) was used, with mouse IgM isotype control (SigmaAldrich, M5909), and rat IgG2ak isotype control (BD Biosciences Pharmingen, 559073) as negative controls.

Experimental design and statistical analysis. The mouse pups of specified age were collected following genotyping, using wild-type (WT) littermates as controls. Sex of the animals was not assessed. Mitotic spindle angles were measured from $0.2 \mu \mathrm{m}$ optical section $z$ stacks acquired using OptiGrid structured illumination microscopy (Improvision) from peripheral regions of 3 retinas per genotype or ex vivo condition, on an Eclipse Ni microscope (Nikon) with $60 \times$ oil-immersion objective at room temperature. $3 \mathrm{D}$ reconstruction, analysis of the dividing nuclei, mitotic spindle angle, and all other measurements were performed using Volocity (PerkinElmer). Centrosomes were defined as objects in 3D space, and spindle angle was measured as an angle between the line

\section{$\leftarrow$}

(Figure legend continued.) Right, XZ view of a mitotic RPC with mathematical approach used to calculate the $3 \mathrm{D}$ angle between the two spindle poles. $\boldsymbol{D}$, Representative images of $X Z$ views of cells with asymmetric (top) and symmetric (bottom) mitotic spindle orientations. E, $F$, Mitotic spindle angle distributions and ratios at P0, P3, and P5. G, Organotypic retinal culture model. After 1 DIV, exogenous laminin, suspended in medium, is added to the retina, which is grown for 2 more days before being collected and analyzed. $\boldsymbol{H}, \boldsymbol{I}$, Mitotic spindle angle distributions and ratios in retinal explants. ${ }^{*} p \leq 0.05,{ }^{* *} p \leq 0.01,{ }^{* * *} p \leq 0.001$. connecting the centroids of the two centrosomes and the plane of the apical surface of the retina.

Angle measurement distributions were compared using KolmogorovSmirnov test. Symmetric versus asymmetric angle ratios were compared using $\chi^{2}$ test. Mitotic densities and ratios of RPCs with BPs were compared using Student's $t$ test (for two-condition comparison) or ANOVAs with Bonferroni's multiple-comparisons test (three or more conditions). Cell-type numbers as well as mitotic indices were calculated by counting cells positive for markers of interest in at least two non-neighboring sections per sample ( 3 or more per genotype per time point) and compared by using Student's $t$ test. Data were represented as mean \pm SEM. Statistical analyses and graphical representations were performed using Prism version 6.0 (GraphPad). Illustrator CS3 and Photoshop CS3 (Adobe) were used for nonquantitative image editing and arrangement, such as image rotation, hue adjustment, and figure composition.

\section{Results}

\section{RPC mitotic spindle orientation is laminin-dependent}

Direction of cytokinesis plays an important role in fate decision, presumably by modulating inheritance of fate-determining factors (Fig. 1A). To determine whether the orientation of RPC cytokinesis is affected by composition of the ILM, we examined the orientation of the mitotic spindle poles, as they are the focal points of separation during cell division, in WT and Lamb2 $2^{-1-}$ mice. Spindle poles in peripheral regions of retinal flat-mounts were visualized using phospho-histone $\mathrm{H} 3{ }^{\mathrm{Ser} 28}$ (PH3) and centrin immunostaining to label mitotic cells and centrosomes, respectively. Mitotic spindle angles of RPCs in prometa/metaphase (Fig. $1 B$ ) were calculated from $z$ stacks by simple trigonometry (Fig. 1C). Angles oriented at $<30^{\circ}$ relative to the apical surface were considered symmetric, whereas those oriented at $>30^{\circ}$ were considered asymmetric (Fig. 1D).

We found that the majority of the spindle angles in WT were oriented symmetrically. In P0 and P3 Lamb2 $2^{-1-}$ retinas, the distribution of the mitotic spindle angles was significantly shifted toward asymmetry (P0: $p=0.0157 ; \mathrm{P} 3: p=0.0003$, Kolmogoro$\mathrm{v}-$ Smirnov test). By P5, however, the spindle angles did not appear different from the WT (Fig. $1 E$ ). Consistent with the angle distribution results, the overall ratios of symmetric and asymmetric angles were shifted toward asymmetry in P0 and P3 Lamb2 ${ }^{-/-}$animals (P0: $p=0.0015 ; \mathrm{P} 3: p=0.0001 ; \chi^{2}$ test) and were unaltered at P5 (Fig. $1 F$ ). These data suggest that $\beta 2$ containing laminins at the ILM provide molecular cues governing the RPC mitotic axis during development.

\section{Exogenous laminin $\beta 2$ rescues RPC mitotic spindle orientation ex vivo}

To confirm our findings and to test whether $\beta 2$-containing laminins at the ILM directly provide orientational cues to the RPCs, we performed rescue studies using an ex vivo approach. Explants were prepared from retinas that were isolated at $\mathrm{P} 0$, and grown with the RPE intact. After $1 \mathrm{DIV}$, exogenous recombinant laminin 521 (trimer containing $\alpha-5, \beta-2$, and $\gamma-1$ chains) was added to the retinal surface, and cultures were grown for 2 more days before being collected and analyzed (Fig. 1G). RPC mitotic spindle orientation was assessed as described above. Similar to in vivo results, the distribution of mitotic spindles in the Lamb2 $2^{-1-}$ cultures was significantly skewed toward asymmetry (WT vs Lamb2 $^{-/-}: p=0.042$, Kolmogorov-Smirnov test). Addition of laminin 521 shifted the spindle angles toward symmetry $\left(\right.$ Lamb2 $^{-1-}$ vs Lamb2 $2^{-1-}+521: p=0.0066$, KolmogorovSmirnov test), resulting in WT-like distribution. This effect was specific to laminin 521, as exogenous laminin $511(\alpha-5, \beta-1, \gamma-1)$ failed to rescue the mitotic spindle orientation in RPCs (Fig. $1 H$ ). 

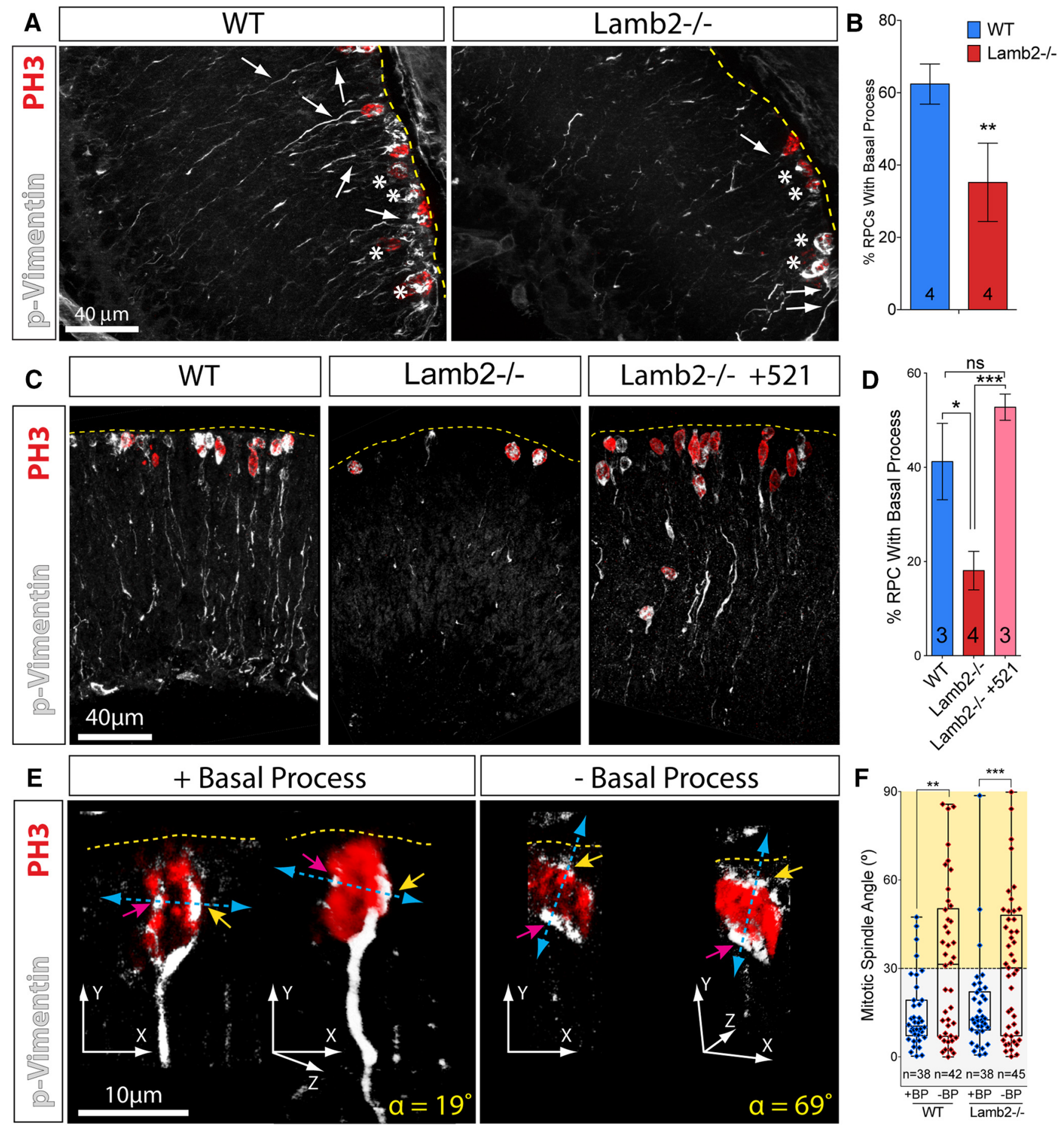

Figure 2. Laminin $\beta 2$ in the ILM regulates BP stability in mitotic RPCs. $A$, Extended focus view of $20 \mu \mathrm{m} z$ stack of $\mathrm{P} 3$ retinal sections stained for $\mathrm{p}$-vimentin (white represents dividing RPCs) and PH3 (red represents mitotic chromatin). Arrows indicate cells with BPs. Asterisk indicates without BPs. Dashed line indicates apical surface of the retina. $B, Q$ uantification of RPCs with BPs at P3. C, Extended focus view of $20 \mu \mathrm{m}$ z stack of p-vimentin and PH3-stained retinal explant sections. D, Quantification of RPCS with BPs in retinal explants. $\boldsymbol{E}$, Optical sections, and 3D volume reconstructions, of mitotic RPCs with and without BPs. Dashed yellow line indicates apical surface of the retina. Arrows indicate mitotic spindle baskets. Dashed blue line with arrowheads indicates the line between the mitotic spindles as well as the direction of cytokinesis. $\alpha$ indicated the mitotic spindle angle for respective RPCs. $F$, Mitotic spindle angle distributions in RPCs with and without BPs in WT and Lamb2 ${ }^{-1-} .{ }^{*} p \leq 0.05,{ }^{* *} p \leq 0.01,{ }^{* * *} p \leq 0.001$.

Consistent with the angle distributions, the overall ratios of symmetric and asymmetric angles were shifted toward asymmetry in Lamb2 $2^{-1-}$ cultures $\left(p=0.0001, \chi^{2}\right.$ test $)$, whereas addition of laminin 521, but not laminin 511, resulted in WT-like ratios ( $p=$ 0.0177, $\chi^{2}$ test) (Fig. 1I). Together, these results demonstrate that the presence of $\beta 2$-containing laminin at the retinal surface is necessary for proper mitotic spindle orientation in RPCs.

\section{Laminin $\beta 2$ contributes to RPC - BM contact}

Having established that laminin-mediated signaling controls RPC mitotic spindle orientation, we proceeded to investigate the mechanisms facilitating this process. RPCs undergo mitosis at the apical surface and span the thickness of the retina, with a BP extending to the BM. We therefore examined whether loss of $\beta 2$-containing laminins affected contact between mitotic RPCs 

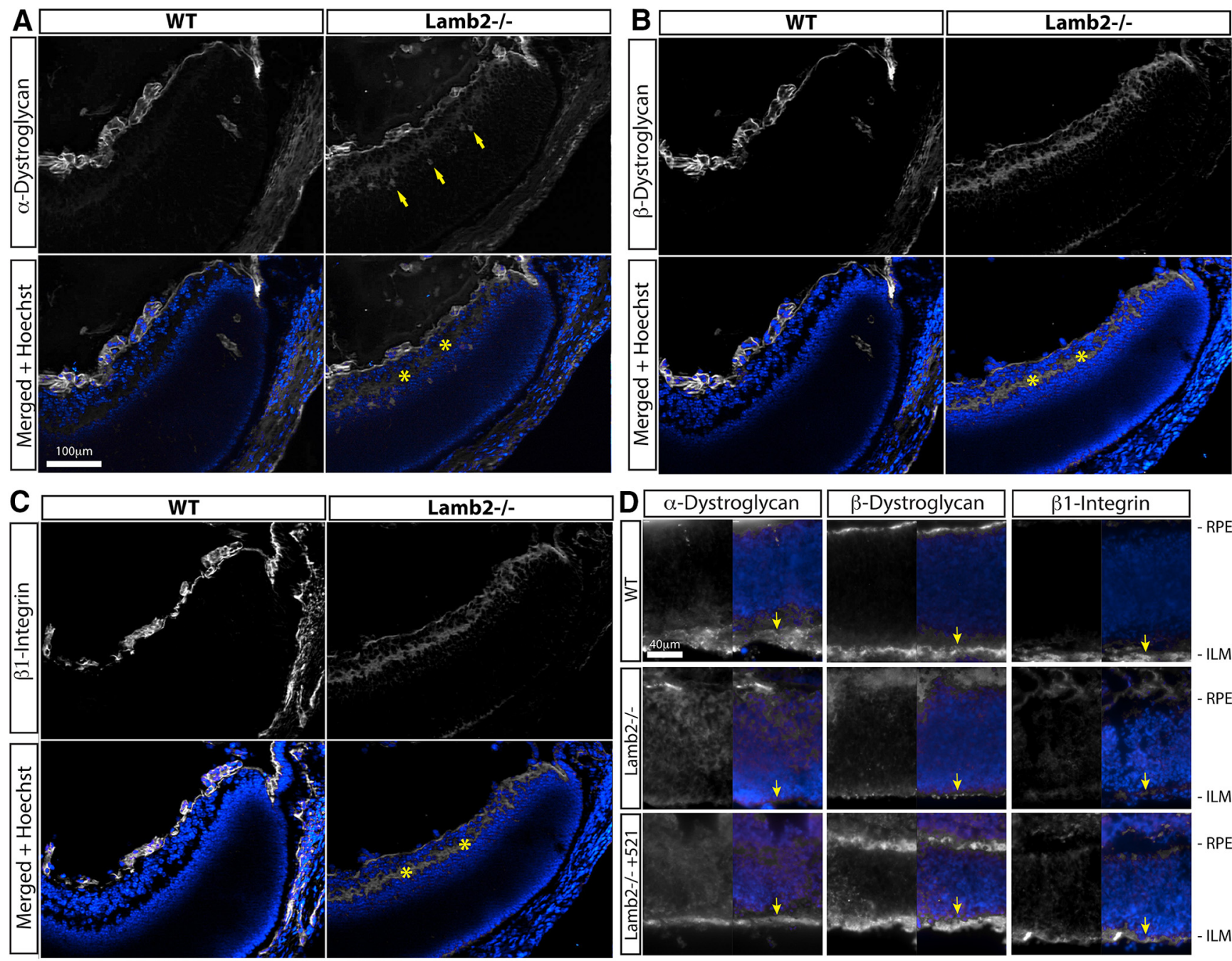

Figure 3. $D G$ and $\beta 1$ integrin localization in the retina is laminin-dependent. $A-C$, Neighboring P3 WT and Lamb2 ${ }^{-/-}$retinal cross sections. $A$, WT and Lamb2 ${ }^{-/-}$retinal sections stained for $\alpha$-DG. In WT retinas, $\alpha$-DG localizes to the vitreal surface on the retina and is also present in the blood vessels. In Lamb2 ${ }^{-1-}$ retinas, $\alpha$-DG staining is discontinuous at the vitreal surface, mislocalized to some cell bodies (arrows) and the IPL (asterisks). B, WT and Lamb2 ${ }^{-\prime-}$ retinal sections stained for $\beta$-DG, which exhibits similar distribution to the $\alpha$-subunit. Mislocalization in Lamb2 $^{-/-}$is similar to that of the $\alpha$-subunit. C, WT and Lamb2 ${ }^{-/-}$retinal sections stained for $\beta 1$-integrin, exhibiting similar localization to that of $\alpha$-DG. $D$, Addition of exogenous laminin rescues $D G$ and $\beta 1$-integrin localization in organotypic retinal cultures. In WT explants, $\alpha-, \beta-D G$, and $\beta 1$-integrin are localized to the basal surface $\left(\boldsymbol{A}-\boldsymbol{D}\right.$, arrows). In Lamb2 ${ }^{-\prime-}$ explants, the staining is largely absent at the basal surface. Receptor localization at the basal surface is rescued in Lamb2 ${ }^{-1-}$ explants with addition of exogenous laminin 521.

and BM. Mitotic RPC morphology was examined by immunostaining with phospho-vimentin ${ }^{\text {Ser55 }}$ to label dividing RPCs and PH3 to label mitotic chromatin in WT and Lamb2 $2^{-/-}$retinal sections (Fig. 2A). We found that the percentage of cells with BPs was significantly decreased in Lamb2 $2^{-1-}$ mutants compared with WT ( $p=0.0042, t$ test) (Fig. $2 B$ ). This suggests that loss of $\beta 2$-containing laminins leads to retraction of BPs by mitotic RPCs.

To test whether $\beta 2$-containing laminins at the retinal surface are directly responsible for mitotic RPC BP presence, we examined Lamb2 ${ }^{-1-}$ RPC BPs in response to exogenous laminin 521 addition using retinal explants (Fig. 2C). Similar to in vivo findings, ex vivo Lamb2 $2^{-1-}$ retinas displayed a significant decrease in mitotic RPCs with BPs compared with WT. Addition of laminin 521 to the surface of $\beta 2$-laminin-deficient cultures led to an increase of mitotic RPCs with BPs, resulting in levels comparable with the WT explants (WT vs Lamb2 $2^{-1-}: p<0.05 ;$ Lamb2 $^{-/-}$vs Lamb2 $2^{-1-}+521: p<0.0001$, ANOVA) (Fig. 2D). These findings suggest that the mitotic RPC BPs are stabilized at the ILM in a laminin-dependent manner, similar to that known for the Müller glia (Pinzón-Duarte et al., 2010).

Loss of BP by the RG in the developing cortex has been shown to be an important step in converting symmetrically dividing RG to stochastically dividing intermediate progenitor cells (IPCs) (Haubensak et al., 2004; Miyata et al., 2004; Noctor et al., 2004, 2008; Wu et al., 2005; Attardo et al., 2008). We therefore examined whether the same mechanisms are present in the retina. Vimentin is an intermediate filament protein that forms baskets surrounding the mitotic spindles (Zieve et al., 1980; Chou et al., 2003). Phospho-vimentin immunostaining thus allowed visualization of the mitotic spindles, as observed by discrete $\mathrm{p}$-vimentin staining on either side of PH3-labeled RPC chromosomes aligned at the metaphase plate, as well as BPs. Mitotic spindle angles were calculated from $z$ stacks of mitotic RPCs by measuring the angle between a line connecting the p-vimentin mitotic spindle baskets and the plane of the apical surface (Fig. $2 E$ ). We found that, in both WT and Lamb2 $2^{-\prime-}$ retinas, mitotic RPCs with BPs predominantly displayed symmetric spindle orientation, whereas those 
lacking BPs were more stochastic (WT: $p=0.0018 ;$ Lamb2 $^{-1-}$ : $p=0.0002$. Kolmogorov-Smirnov test) (Fig. $2 F$ ). These findings demonstrate that loss of the BPs by mitotic RPCs leads to a loss of symmetric spindle orientation, suggesting that the spindle angle phenotype observed in $\mathrm{Lamb2}^{-1-}$ retinas is due to an increased incidence of mitotic RPCs lacking BPs.

\section{DG and $\beta 1$-integrin localization is laminin-dependent}

Having established that loss of $\beta 2$-containing laminins leads to loss of BPs in mitotic RPCs, and a shift of mitotic spindle angles toward asymmetry, we proceeded to investigate the molecular mechanisms by which laminins normally regulate mitotic spindle orientation. Disruption of cell-BM contact would necessarily disrupt the molecular signaling between cell-surface receptors and their ligands. As an ECM molecule, laminins interact with cells mainly via $D G$ and integrins. Effects of integrin-mediated signaling on cell polarity and division orientation have been noted in numerous studies (for review, see Manninen, 2015). Additionally, depletion of DG and $\beta 1$-integrin in the developing retina mimics several Lamb2 deletion phenotypes (Libby et al., 1999; Li and Sakaguchi, 2004; Lunardi et al., 2006; Pinzón-Duarte et al., 2010). Because laminins are known to regulate their own receptor expression (Condic and Letourneau, 1997), we asked whether Lamb2 deletion affects DG and $\beta 1$-integrin.

In the WT retina, $\alpha$-DG was localized at the vitreal surface as well as in the vascular BMs. In contrast, in the $\mathrm{Lamb2}^{-1-}$ retina, the receptor appeared discontinuous at the vitreal surface, mislocalized to the IPL, and was present in cell bodies of retinal cells (Fig. 3A). $\beta$-DG in the WT retinas assumed the same distribution as the $\alpha$ subunit and was similarly disrupted in the Lamb2 $2^{-1-}$ retinas: discontinuous at the vitreal surface and mislocalized to the IPL (Fig. 3B). Similar to $\beta$-DG, $\beta 1$-integrin was localized to the vitreal surface in WT and was disrupted in $\mathrm{Lamb2}^{-/-}$retinas in a similar pattern (Fig. $3 C$ ). Together, these data demonstrate that the loss of laminin $\beta 2$ in the retina results in mislocalization of DG and $\beta 1$-integrin.

To test whether the observed receptor disruptions are directly due to loss of laminin $\beta 2$ from the ILM, we performed ex vivo rescue studies and analyzed the receptor distribution in cross sections. Both DG and $\beta 1$-integrin were localized at the ILM of the WT retinal explants. Similar to in vivo observations, the receptors were largely absent from the ILM side in $\mathrm{Lamb2}^{-1-}$ cultures. Addition of exogenous laminin 521 to the retinal surface of the Lamb2 $2^{-/-}$explants rescued the proper localization of receptors at the ILM, resulting in a distribution similar to the WT (Fig. $3 D$ ). Together, these data demonstrate that $\mathrm{DG}$ and $\beta 1$-integrin localization in the retina is laminin $\beta 2$-dependent and raise the possibility that these receptors are the mediators of laminin signaling controlling the mitotic axis in RPCs.

\section{$\beta 2$-containing laminins control RPC mitotic spindle orientation via DG}

To test whether $\beta 2$-containing laminins control mitotic spindle orientation via DG and $\beta 1$-integrin, we performed a series of receptor function-blocking experiments. To elucidate the role of each receptor, we used the organotypic culture approach, where WT retinas were treated with either $\alpha$-DG (IIH6) or $\beta 1$-integrin (9EG7) function blocking antibodies. Blocking $\alpha$-DG signaling resulted in a significant spindle angle shift toward asymmetry ( $p=0.0001$, Kolmogorov-Smirnov test), whereas, surprisingly, blocking $\beta 1$-integrin function had no effect. Blocking both pathways resulted in an angle distribution similar to that of blocking $\alpha$-DG signaling ( $p=0.0001$, Kolmogorov-Smirnov test) (Fig.
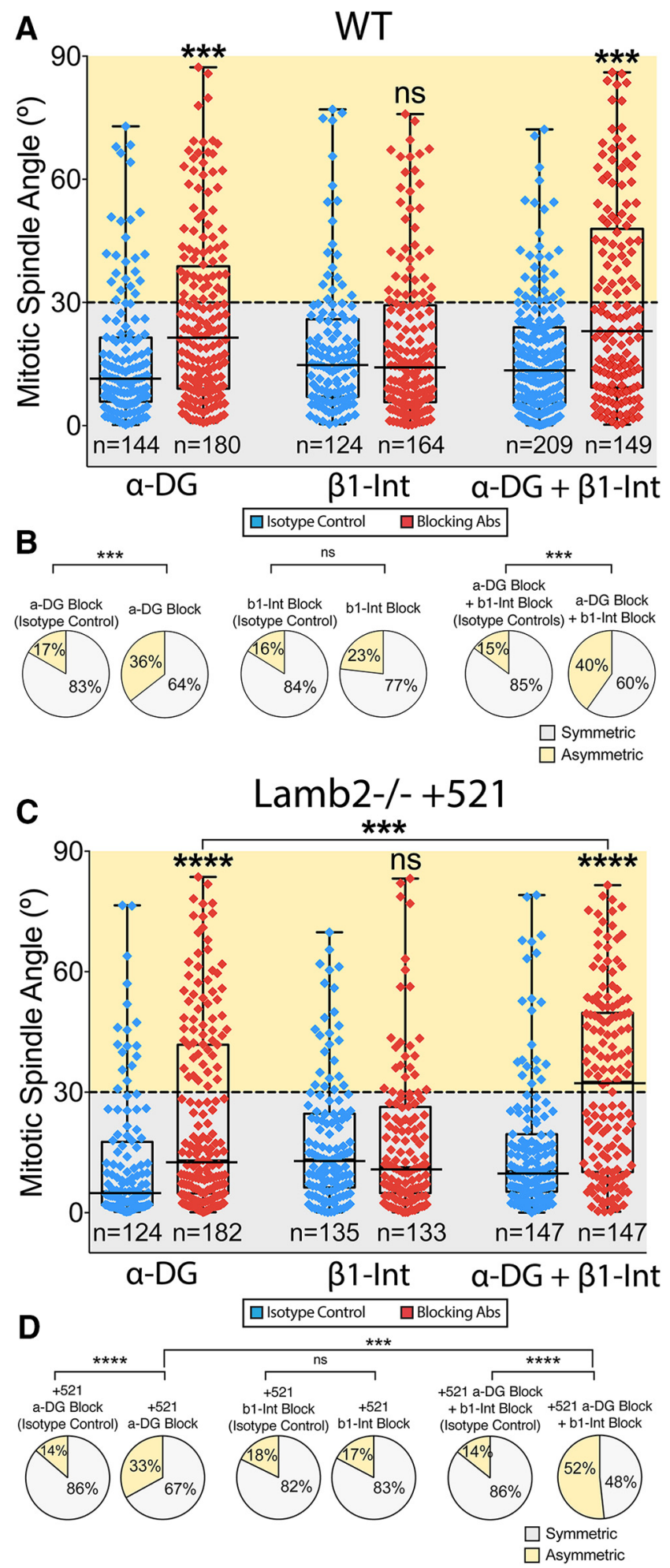

Figure 4. $\quad \beta 2$-containing laminins orient RPC mitotic spindle via DG. $\boldsymbol{A}$, Mitotic spindle angle distributions in WT retinal explants with $\alpha$-DG and $\beta 1$-intergin function-blocking antibodies. $\boldsymbol{B}$, Quantification of ratios of symmetric and asymmetric spindle angles in WT retinal explants. C, Mitotic spindle angle distributions in Lamb2 $2^{-1-}$ retinal explants that have been rescued by laminin 521 addition, with $\alpha$-DG and $\beta 1$-intergin function-blocking antibodies. $D$, Quantification of ratios of symmetric and asymmetric spindle angles in retinal explants. ${ }^{* * *} p \leq 0.001,{ }^{* * * *} p \leq 0.0001$.

$4 A$ ). Consistent with the angle distribution results, the angle ratios were shifted toward asymmetry in $\alpha$-DG, but not $\beta 1$-integrin blocking cultures ( $\alpha$-DG: $p=0.001$; both antibodies: $p=0.001$, $\chi^{2}$ test) (Fig. $4 B$ ). These data suggest that $\beta 2$-containing laminins 

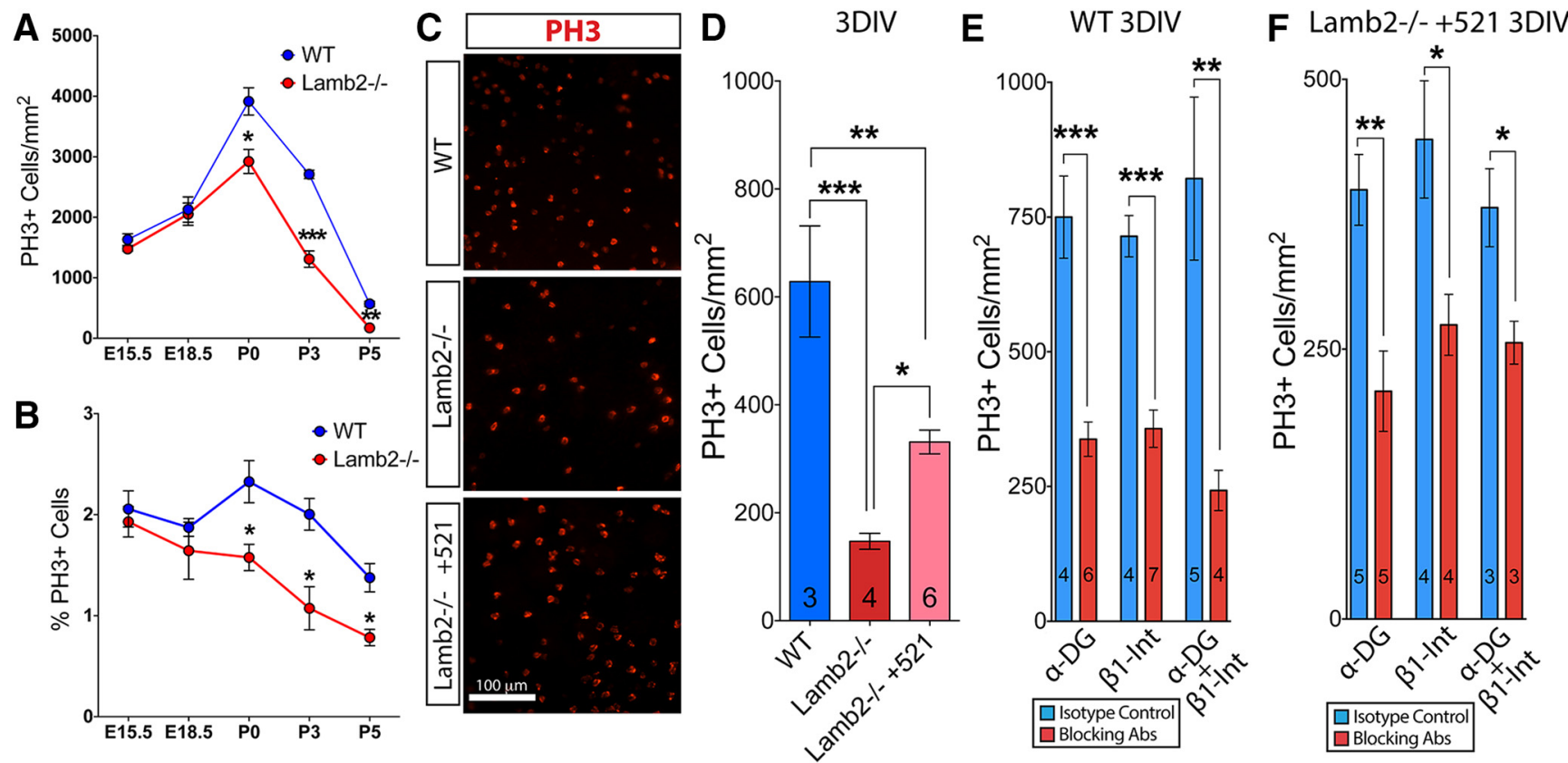

Figure 5. $\beta 2$-containing laminins regulate RPC proliferation via DG and $\beta 1$-intergin. $\boldsymbol{A}$, Mitotic density quantification of WT and $L a m b 2^{-/-}$retinal flat-mounts. $\boldsymbol{B}$, Mitotic index quantification of WT and Lamb2 ${ }^{-1-}$ retinal cross sections. $n \geq 3$ per measurement. $C$, PH3 staining of mitotic RPCs at the apical surface of flat-mounted retinal explants. $\boldsymbol{D}$, Quantification of mitotic densities in retinal explants. $\boldsymbol{E}$, Quantification of mitotic densities in WT retinal explants with $\alpha$-DG and $\beta 1$-intergin function blocking antibodies. $\boldsymbol{F}$, Quantification of mitotic densities in Lamb2 ${ }^{-/-}$retinal explants that have been rescued by laminin 521 addition, followed by $\alpha-D G$ and $\beta 1$-intergin function blocking antibodies. Data are mean \pm SEM. ${ }^{*} p \leq 0.05,{ }^{* *} p \leq 0.01,{ }^{* * *} p \leq 0.001$.

direct RPC mitotic spindle orientation via DG, but not $\beta 1$ integrin. To our knowledge, this is the first report of DGmediated signaling affecting the orientation of the mitotic spindle in any cell type.

Following these results, we proceeded to investigate whether $\beta 2$-containing laminins control RPC mitotic spindle orientation via DG. To this end, we used Lamb2 $2^{-1-}$ explants that have been rescued by exogenous laminin 521 . We hypothesized that, if DG is the mediator for $\beta 2$-containing laminins directing RPC mitotic axis, then blocking DG would be sufficient to reverse the rescue by exogenous laminin addition. Indeed, blocking $\alpha$-DG signaling after laminin 521 addition resulted in a significant spindle angle shift toward asymmetry $(p=0.0001$, Kolmogorov-Smirnov test); on the other hand, $\beta 1$-integrin blocking did not have an effect. Blocking both signaling pathways resulted in a nearly stochastic angle distribution (control vs compound block: $p=$ $0.0001 ; \alpha$-DG block vs compound block: $p=0.0001$; Kolmogorov-Smirnov test), suggesting a synergistic effect between $\alpha$-DG and $\beta 1$-integrin signaling pathways in $\mathrm{Lamb}^{-/-}$retinas (Fig. $4 C)$. Concomitantly, the ratio of symmetric and asymmetric angles was shifted toward asymmetric in $\alpha$-DG block cultures ( $p=$ $0.0001, \chi^{2}$ test), but not $\beta 1$-integrin blocking alone, cultures (Fig. $4 D)$. Compound receptor blockade resulted in a nearly 1:1 ratio between symmetric and asymmetric divisions, similar to the angle distributions. These data demonstrate that the rescue observed with addition of laminin 521 is completely reversed by $\alpha$-DG blocking. Together, these experiments confirm that $\beta 2$ containing laminins control RPC mitotic spindle orientation via DG.

\section{B2-Containing laminins control RPC proliferation}

Having established the DG-mediated effect of $\beta 2$-containing laminins on RPC mitotic axis, we proceeded to investigate whether the observed phenotypes broadly affected retinal development. As mitotic axis orientation is implicated in cell decisions between cell cycle reentry and exit, we examined RPC proliferation throughout development. Mitotic cells were labeled using PH3, and the density of mitotic cells at the retinal apical surface was established by counting the numbers of $\mathrm{PH} 3^{+}$cells in flatmounted retinas. While no effect was observed during embryonic stages, from P0 onward, the density of mitotic cells at the apical retinal surface was significantly decreased (P0: $p=0.0296$; P3: $p=0.0007$; P5: $p=0.0052, t$ test) (Fig. 5A), leading to nearexhaustion of the progenitor pool by P5. Furthermore, mitotic indices were calculated in retinal sections as a percentage of $\mathrm{PH}^{+}$cells in the neuroblast layer at the same time points and were found to be decreased as well (P0: $p=0.0377$; P3: $p=$ 0.0244; P5: $p=0.0213$, $t$ test) (Fig. $5 B$ ). Together, these data indicate a decrease in RPC proliferation in $\mathrm{Lamb2}^{-/-}$retinas.

To assess whether the proliferation decrease is directly due to the loss of laminin $\beta 2$, we again used the ex vivo approach, first we examined RPC proliferation in untreated cultures and then again after exogenous laminin rescue. Similar to our in vivo observations, mitotic density in Lamb2 $2^{-1-}$ retinal explants was significantly lower than in the WT explants. Addition of laminin 521 to Lamb2 $2^{-1-}$ retinal cultures resulted in a significant increase of RPC mitotic density (WT vs Lamb2 $2^{-/-}: p<0.0001 ;$ Lamb2 $^{-/-}$ vs Lamb2 $2^{-/-}+521: p=0.0246$, ANOVA) (Fig. $5 C, D$ ). As explants were prepared from $\mathrm{P} 0$ retinas, it is not surprising that laminin addition did not rescue proliferation to WT levels because mitotic density is already decreased at that age (Fig. $5 A$ ). This effect was specific to laminin 521, as exogenous laminin 511 had no effect on RPC proliferation (data not shown). Together, these findings demonstrate that $\beta 2$-containing laminins directly provide proliferative cues to the RPCs.

\section{DG and $\beta 1$-integrin control RPC proliferation}

Having established the role of $\beta 2$-containing laminins in RPC proliferation, we next examined the roles DG and integrins play in mediating this effect. Using the ex vivo approach, we per- 

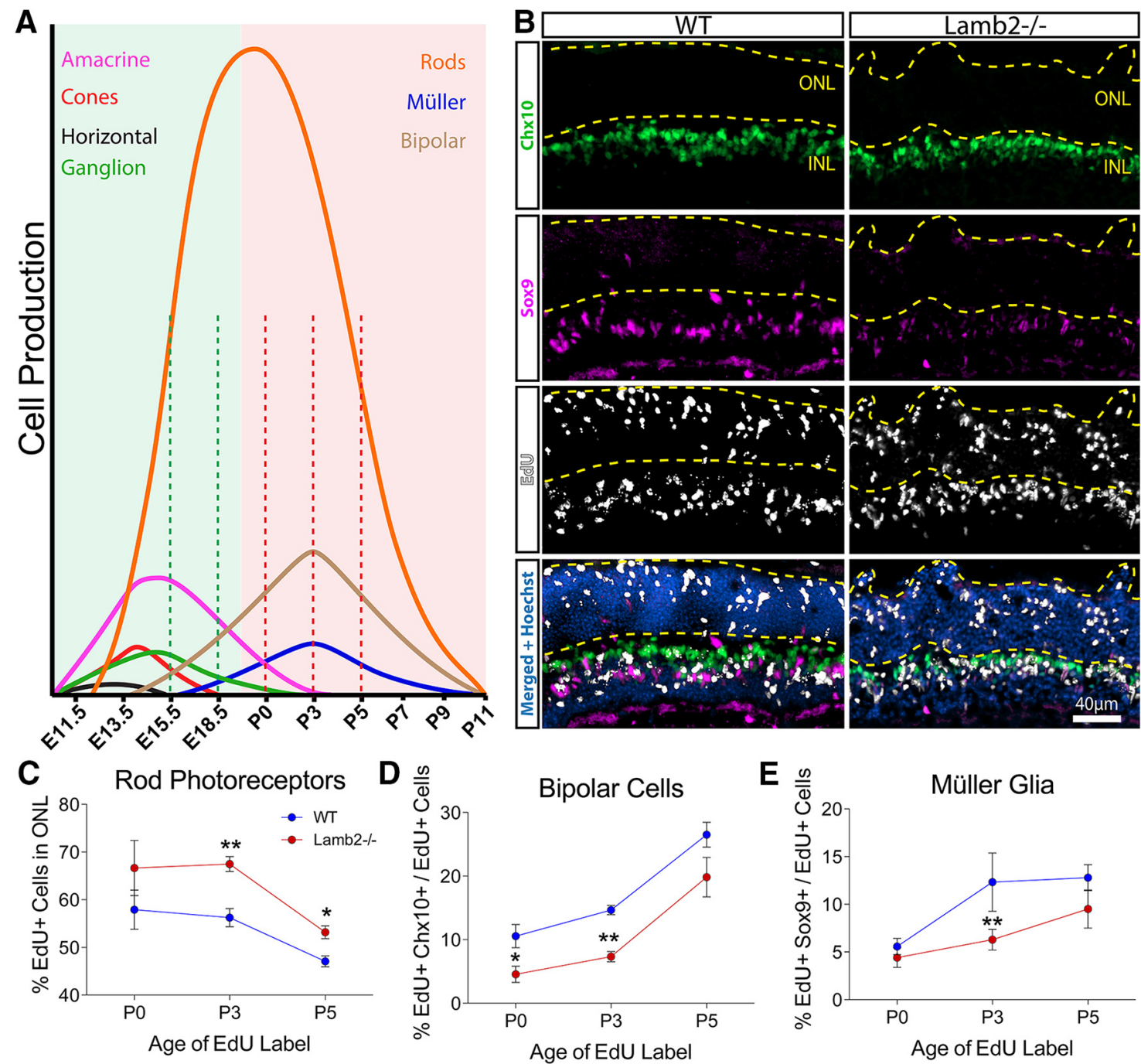

Figure 6. Laminin $\beta 2$ deletion alters RPC cell fate. $\boldsymbol{A}$, Schematic of the developmental progression of cell type differentiation in mouse retina. Modified with permission from Young (1985). Dashed lines indicate time points at which mitotic densities and indices were measured. Green represents unaltered proliferation. Red represents diminished proliferation in Lamb2 ${ }^{-\prime-}$ retinas compared with WT. B, Example of fate-tracking experiment where mice were injected with EdU at P0. Chx10, bipolar cells (green); Sox9, Müller glia (purple). Dashed lines delineate 0NL, which is dysmorphic in Lamb2 ${ }^{-1-}$ retinas. C-E, Quantification of the fate-tracking experiments with proliferating RPCs labeled at PO-P3-P5. Relative percentages of labeled cells at each time point that are located in the $0 \mathrm{NL}$ - rods $(\boldsymbol{C})$, double-labeled EdU/Chx10 bipolar cells in the INL $(\boldsymbol{D})$, and double-labeled EdU/Sox9 Müller glia in the INL $(\boldsymbol{E}) . n \geq 3$ for all data points. Data are mean \pm SEM. ${ }^{*} p \leq$ $0.05,{ }^{* *} p \leq 0.01$.

formed receptor blocking assays and assessed RPC proliferation. $\alpha$-DG blocking of WT retinal cultures resulted in a significant decrease in mitotic cell density compared with the isotype controls $(p=0.0004, t$ test). Similarly, $\beta 1$-integrin blocking also resulted in a significant decrease in mitotic cell density $(p=$ $0.0001, t$ test). Combining the two treatments decreased the mitotic cell density ( $p=0.0128, t$ test $)$, but not significantly more so than the single treatments (Fig. $5 E$ ), suggesting that DG and $\beta 1$ integrin-mediated signaling is involved in regulating RPC proliferation.

Next, we examined whether DG and $\beta 1$-integrin-mediated the rescue of RPC proliferation in Lamb2 ${ }^{-1-}$ cultures by exogenous laminin 521 (Fig. 5D). To do this, we performed receptor blocking experiments in Lamb2 $2^{-/}$cultures after exogenous laminin 521 was added (Fig. 5F). Similar to the results observed in WT cultures, control antibodies had no effect, whereas blocking of $\alpha$-DG and $\beta 1$-integrin resulted in decreased RPC mitotic density ( $\alpha$-DG: $p=0.0056 ; \beta 1$-integrin: $p=0.0309, t$ test), with effects not appearing to be additive (Fig. $5 F$ ). Reversing the res- cue effects of laminin 521 by blocking these receptors indicated that RPC proliferation control is indeed mediated through them.

\section{Deletion of Lamb2 leads to RPC cell-fate shift}

Having established the role of $\beta 2$-containing laminins in RPC mitotic spindle orientation and proliferation, we next proceeded to assess whether the observed RPC behavior ultimately resulted in alteration of the developmental program in the Lamb2 $2^{-1-}$ retina. As the observed RPC pool decline coincides with the time of peak rod, bipolar, and Müller cell production (Fig. 6A), we inspected these cell populations using a fate-tracking approach to investigate RPC fate choices. WT and Lamb2 ${ }^{-1-}$ pups were injected with EdU at P0, P3, or P5, and allowed to grow to P15. At that time, the retinas were harvested, sectioned, and stained for EdU, Chx10 (bipolar cell), and Sox9 (Müller glia) to establish the ratios of cell types born at each age (Fig. 6B). The relative percentages of RPCs that became rods were significantly increased in P3 $(p=0.0016, t$ test $)$ and P5 ( $p=0.0157, t$ test $)$ injected Lamb2 ${ }^{-\prime-}$ retinas (Fig. $6 C$ ). At the same time, RPCs that adopted bipolar cell 

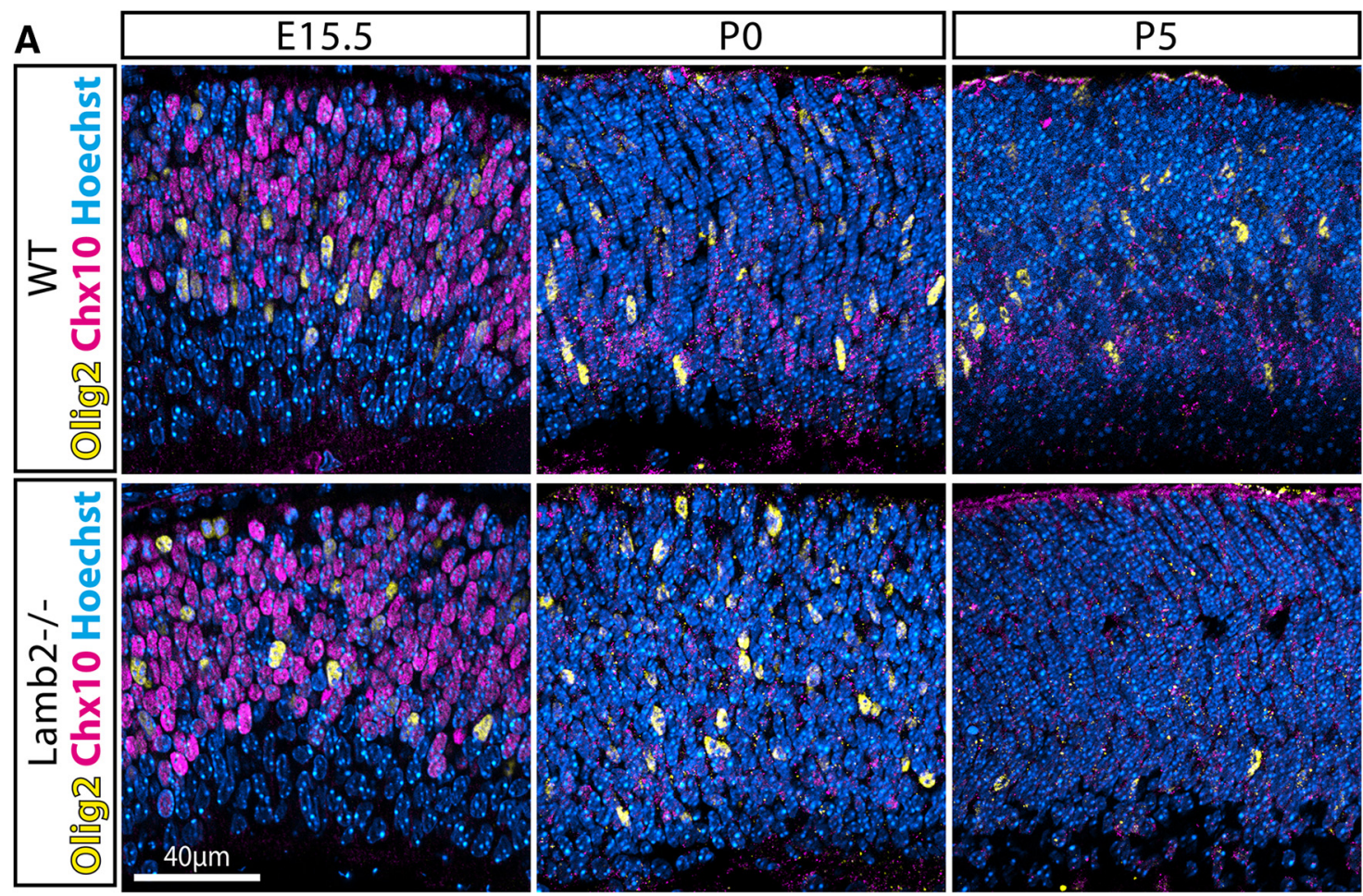

B

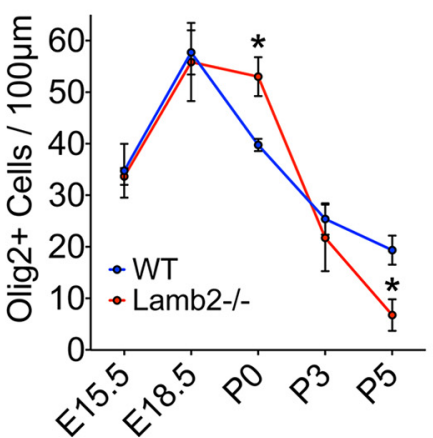

C

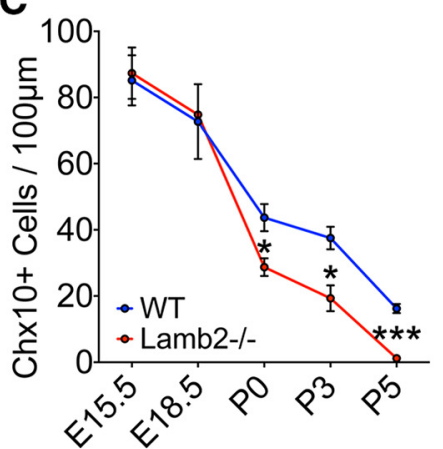

D

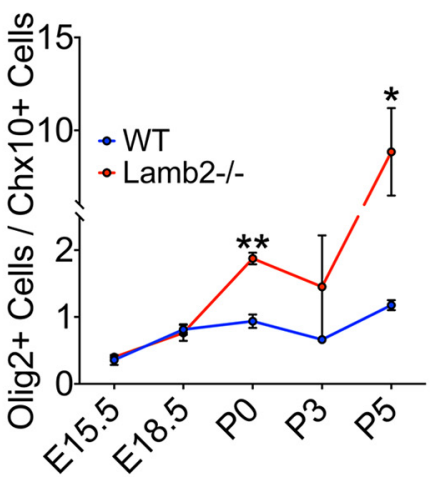

Figure 7. Laminin $\beta 2$ deletion shifts RPCs toward 0lig ${ }^{+}$lineage. $A, E 15.5-P 5$ developmental series of retinal cross sections stained for 0 lig 2 and Chx 10. The numbers of 0 lig ${ }^{+}$and $C h x 10{ }^{+}$cells were determined by counting in cross sections. B, Quantification of Olig2 ${ }^{+} \mathrm{RPC}$. The numbers of 0 lig2 ${ }^{+}$cells were unaffected during embryogenesis but were altered during the postnatal development in Lamb2 $2^{-1-}$ retinas. C, Quantification of Chx10 ${ }^{+} \mathrm{RPCS}$. The numbers of Chx10 ${ }^{+}$cells were unaffected during embryogenesis but declined more rapidly during postnatal development in Lamb2 ${ }^{-1-}$ retinas. D, Ratio of Olig ${ }^{+} \mathrm{RPCs}$ to Chx10 ${ }^{+} \mathrm{RPCs}$ throughout development. The ratios were unaffected during embryogenesis but became significantly increased during postnatal development in Lamb2 ${ }^{-/-}$retinas. Data are mean \pm SEM. ${ }^{*} p \leq 0.05,{ }^{* *} p \leq 0.01$.

fate were reduced in P0 ( $p=0.0277, t$ test $)$ and $\mathrm{P} 3(p=0.0006$, $t$ test) injected Lamb2 $2^{-1-}$ retinas (Fig. $6 D$ ). The relative percentage of Müller glia produced was decreased in P3 $(p=0.0424, t$ test) injected Lamb2 $2^{-/-}$retinas (Fig. $6 E$ ). Together, these findings indicate that the absence of laminin $\beta 2$ shifts RPC fate toward production of rods and away from the later-born bipolar and Müller cells, consistent with premature cell cycle exit.

\section{Deletion of Lamb2 leads to RPCs to shift toward Olig2 ${ }^{+}$lineage}

Having observed RPC cell-fate shift in $L a m b 2^{-1-}$ retinas, we proceeded to further investigate the mechanisms responsible for the apparent preferential rod production. The majority of rods are produced by an Olig ${ }^{+}$subpopulation of terminally dividing RPCs (Hafler et al., 2012). We therefore investigated whether Lamb2 deletion affected this RPC population. To do so, we labeled retinal cross sections, ages from E15.5 to P5, with Olig2 (terminally dividing, primarily rod-producing RPCs) and Chx10 (multipotent RPCs) (Rowan and Cepko, 2004) to assess the changes in these RPC populations throughout development. During embryonic development, both populations were clearly visible by immunostaining. From P0 onward, however, Chx10 immunofluorescence became faint, with decreasing numbers of labeled cells (Fig. 7A). Consistent with no observed defects in embryonic development, numbers of Olig2 ${ }^{+}$RPCs did not differ between WT and $\mathrm{Lamb2}^{-/-}$retinas. While the density of Olig2 ${ }^{+}$ RPCs begins to decline in WT retinas at P0, when Olig2 ${ }^{+}$RPCs almost exclusively give rise to rods (Hafler et al., 2012), it remained significantly higher in Lamb2 ${ }^{-/-}$retinas $(p=0.0284, t$ test), followed by a rapid decline, ending with a significant decrease by P5 ( $p=0.088, t$ test) (Fig. $7 B)$. At the same time, the density of Chx10 ${ }^{+}$RPCs was unaffected in embryonic Lamb2 ${ }^{-/-}$ retinas but declines more rapidly during postnatal development $(\mathrm{P} 0: p=0.0378$; $\mathrm{P} 3: p=0.0250 ; \mathrm{P} 5: p=0.0004, t$ test) (Fig. $7 C$ ). Finally, the ratio of Olig2 ${ }^{+}$to $\mathrm{Chx} 10^{+} \mathrm{RPCs}$, which describes the relationship between restricted and multipotent progenitors, re- 

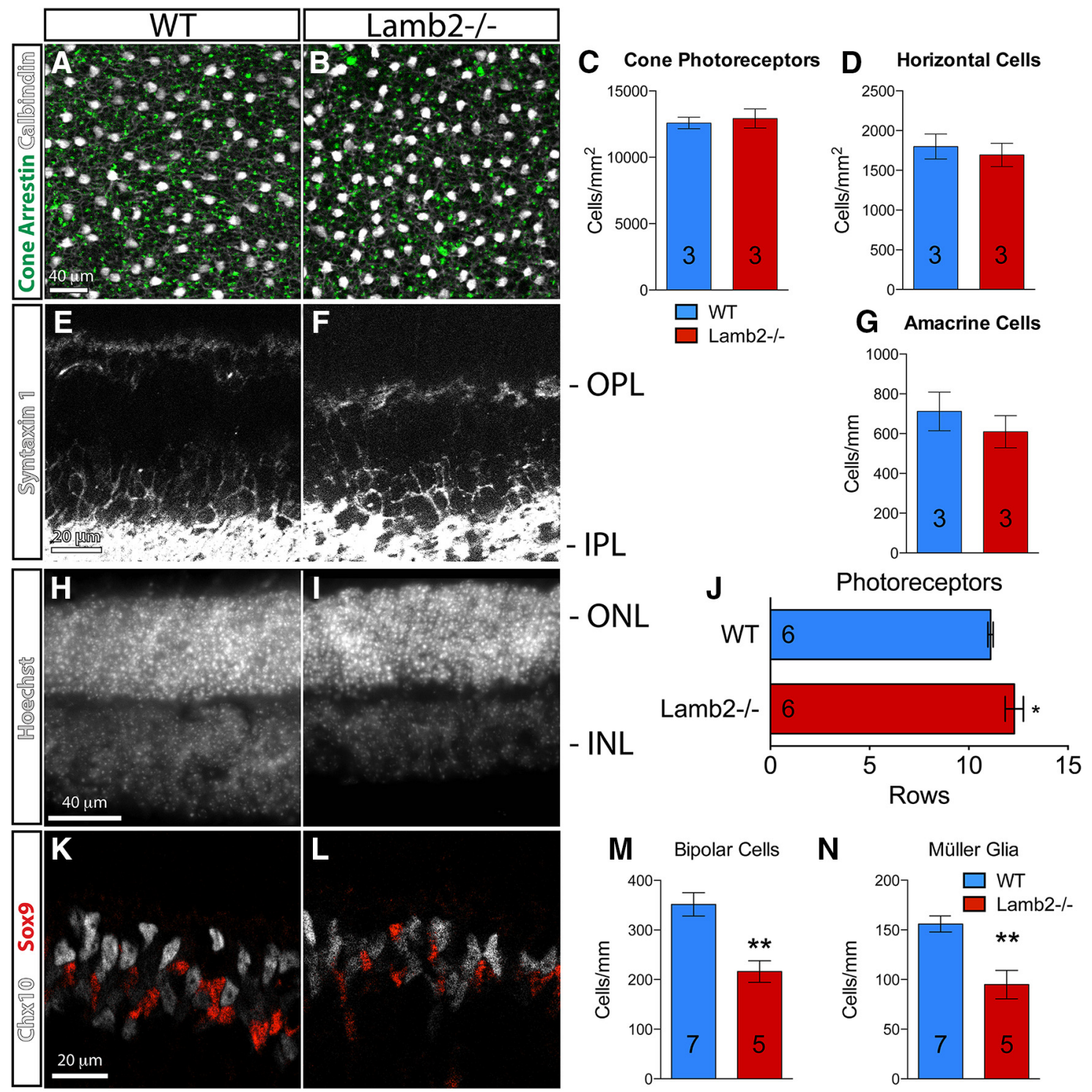

Figure 8. Deletion of laminin $\beta 2$ leads to overproduction of rod photoreceptors and underproduction of bipolar cells and Müller glia. $A, B$, Extended focus view of $z$ stacks from OPL and adjacent part of INL in flat-mount retinas stained for calbindin (horizontal cells) and cone arrestin (cone photoreceptors). The numbers of horizontal cells and cone photoreceptors were determined by counting in retinal flat-mounts and were found to be unaffected in the Lamb2 $2^{-1-}$ retinas. $C, D$, Quantification of cone photoreceptor and horizontal cell densities. $E$, $F$, Syntaxin- 1 staining of retinal sections labeling amacrine cells. $G$, Quantification of the amacrine cell numbers. $\boldsymbol{H}, \boldsymbol{I}$, Hoechst staining of retinal cross sections. $\boldsymbol{J}$, Quantification of rows of cells in the photoreceptor layer. $\boldsymbol{K}, \boldsymbol{L}$, Chx 10 (bipolar cells) and Sox9 (Müller glia) staining of retinal cross sections. $M, N$, Quantification of bipolar cells and Müller glia. Data are mean \pm SEM. ${ }^{*} p \leq 0.05,{ }^{* *} p \leq 0.01$.

mained unchanged during embryogenesis and significantly increased in the postnatal Lamb2 ${ }^{-1-}$ retinas (P0: $p=0.0021$; P5: $p=0.0223, t$ test) (Fig. 7D). Together, these data suggest that Lamb2 deletion results in a shift of RPC cell-fate from multipotent to fate-restricted Olig2 ${ }^{+}$lineage during postnatal retinogenesis, consistent with overproduction of rods and premature RPC pool depletion.

\section{Deletion of Lamb2 leads to altered cellular composition of the retina}

To assess whether the RPC cell-fate shift observed in Lamb2 ${ }^{-/-}$ mice ultimately affected the cellular composition of the retina, we compared the numbers of retinal cell types in WT and Lamb2 $2^{-\prime-}$ retinas. Consistent with no observed defects in embryonic development of the mutant retinas, numbers of early-born cell types were unaffected. Overall numbers of cone photoreceptors and horizontal cells, as determined by counting Cone Arrestin ${ }^{+}$or
Calbindin ${ }^{+}$cells in retinal flat-mounts, respectively (Fig. $8 A, B$ ), were not altered in $\mathrm{Lamb2}^{-1-}$ mice (Fig. 8C,D). Numbers of amacrine cells, as determined by counting Syntaxin $1^{+}$cells in retinal cross sections (Fig. 8E,F), were slightly, though not significantly, reduced (Fig. $8 G$ ). This is consistent with our previous observations that $\mathrm{TH}^{+}$amacrine cell numbers, which make up a small fraction of the amacrine cell population, are reduced in Lamb2 ${ }^{-1-}$ retinas (Dénes et al., 2007). The number of rod photoreceptors was determined by the standard method of counting rows of nuclei in the ONL in cross sections (Fig. $8 \mathrm{H}, \mathrm{I}$ ), as up to $97 \%$ of them are rods (Carter-Dawson and LaVail, 1979). Consistent with fate tracking studies, the number of photoreceptor rows was increased in mutant retinas ( $p=0.0308, t$ test) (Fig. $8 J$ ). At the same time, numbers of bipolar cells and Müller glia, as determined by counting Chx $10^{+}$or Sox $9^{+}$cells in cross sections (Fig. $8 K, L$ ), were significantly decreased (bipolar: $p=0.0023$; Müller: $p=0.0026, t$ test) (Fig. $8 M, N$ ). These data suggest that 
A

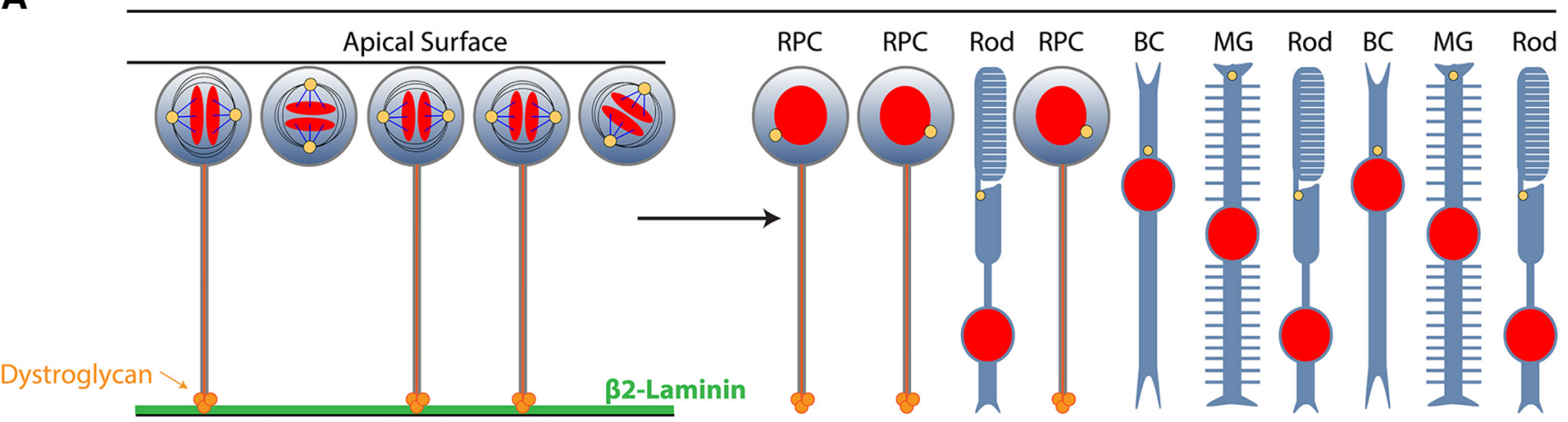

Basement Membrane (ILM)

B

Lamb2-/-

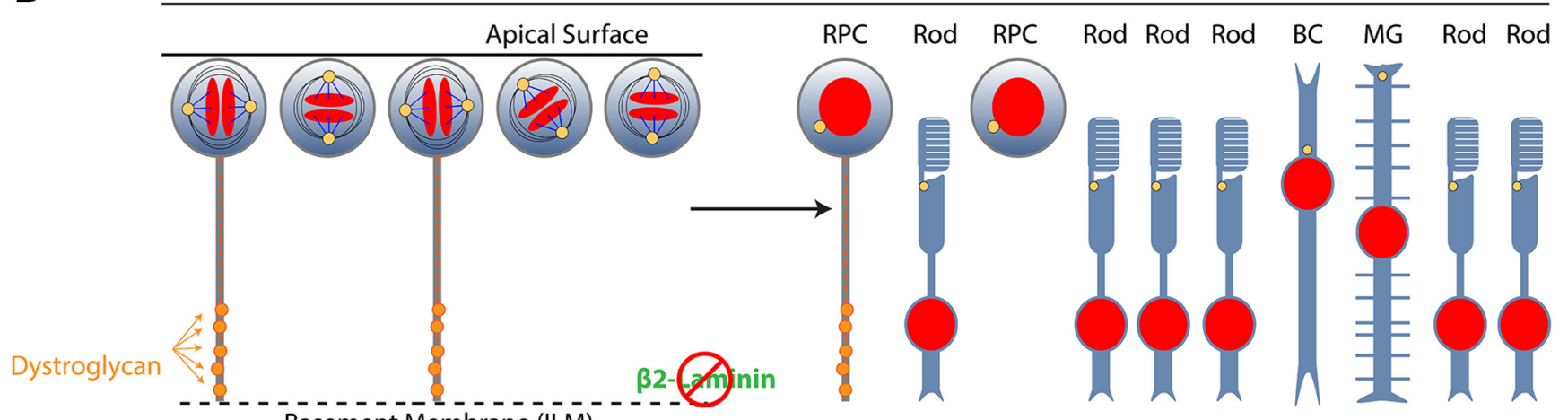

Basement Membrane (ILM)

Figure 9. Laminin $\beta 2$ regulates RPC proliferation and cell fate decision by modulating mitotic spindle orientation via DG. Contact between mitotic RPCs and the ILM is established through the BP, and the signaling is mediated via multiple receptors. This interaction provides orientational and signaling cues ensuring proper retinal development. $A$, DG regulates the orientation of the RPC mitotic spindle. Most cell divisions are symmetric, contributing to the progenitor pool maintenance and ensuring orderly cell cycle exit during development. $\boldsymbol{B}$, Loss of laminin $\beta 2$ leads to disrupted ILM, which fails to provide proper cues to the mitotic RPCs. Mitotic RPCs lose their BPs, disrupting DG-mediated signaling. As a result, the mitotic axis shifts toward asymmetry, accompanied by cell cycle exit. This leads to overproduction of rods at the expense of the bipolar cells (BC) and Müller glia (MG).

Lamb2 deletion results in premature progenitor pool depletion and overproduction of rod photoreceptors at the expense of the late-born bipolar cells and Müller glia. Together, these data demonstrate that $\beta 2$-containing laminins provide critical epigenetic cues for RPCs that govern mitotic axis, proliferation, and the ensuing fate choice to ensure proper developmental progression.

\section{Discussion}

In recent years, our understanding of tissue development as a process occurring within a complex $3 \mathrm{D}$ environment has been greatly expanded. Classical in vitro studies performed with cellular monolayers have revealed important conceptual and mechanistic details regarding cell processes and behavior. However, the discrepancy between cell behavior in classical cultures and those grown with ECM cues, or more recently, 3D matrices, cannot be overstated. Initial data describing the role of laminins in establishing epithelial polarity came from studies in the kidney glomeruli, where blocking laminin- $\alpha$ chain signaling inhibited cell polarization in organ cultures (Klein et al., 1988). Compelling evidence from studies in 3D Madin-Darby Canine Kidney cell culture system revealed that laminins are required for the formation of epithelial cysts that elaborate apical surfaces facing an internal lumen. When grown without ECM, these cells fail to polarize properly, but addition of exogenous laminin rescues the polarity defects (Wang et al., 1990; O'Brien et al., 2001). Another example of implementation of these principles includes mammary epithelial cell cultures. Grown on 2D plastic, they fail to express tissue-specific proteins or form acinar-like structures. However, when grown on a laminin-rich 3D matrix, they assemble into in vivo-like structures with a number of mammaryspecific properties (Xu et al., 2009). 3D ECM-containing cultures have also been used to generate organotypic models recapitulating in vivo tissue architecture and polarization (Griffith and Swartz, 2006), opening new avenues to study development, regeneration, and tissue engineering.

Possibly the most notable example of the importance of laminin as it relates to retinal development and organization was the use of laminin to recapitulate eyecup formation from embryonic stem cells. Specifically, growing neurospheres on artificial ECM caused them to laminate and organize into retina-like structures (Eiraku et al., 2011). Our findings provide mechanistic explanation for this result and thereby further the appreciation for the importance of laminins as not only mechanical and structural support, but in providing epigenetic signaling cues.

Here, we have identified the molecular signaling mechanism by which $\beta 2$-containing laminins in the ILM modulate RPC mitotic axis and thereby neurogenesis in the retina, shedding light on a fundamental process of ECM-cell signaling and the receptors involved. We have established the following: (1) laminindependent contact with BM governs the mitotic spindle orientation; (2) DG-mediated signaling is responsible for coordination of RPC mitotic spindle orientation independently of $\beta 1$-integrin; (3) DG and $\beta 1$-integrin signaling controls RPC proliferation; 
and (4) ILM composition is important for maintaining RPC proliferation and the ensuing cellular composition of the retina. Figure 9 presents a schematic summary of these findings.

\section{Laminins control RPC proliferation and mitotic spindle orientation}

Symmetric cell divisions are required for proper tissue expansion and morphogenesis during development (Baena-López et al., 2005; Segalen and Bellaïche, 2009). Positioning of the mitotic spindle dictates the direction of cytokinesis of the mother cell. Most epithelial stem and progenitor cells orient their spindles perpendicular to the apical-basal axis of the cell and divide parallel to the plane of the tissue, resulting in symmetric tissue expansion and maintenance of the progenitor pool, followed by a switch to asymmetric division mode in later development to generate cellular diversity. This is true in multiple tissues and species (Gillies and Cabernard, 2011). Asymmetric divisions lead to adoption of different fates by the two daughter cells, leading to production of different cell types, and creating functional tissues.

The importance of $\beta 1$-integrin-mediated signaling between ECM and the cell on mitotic spindle positioning in particular has been well documented in numerous systems (Aszodi et al., 2003; Lechler and Fuchs, 2005; Théry et al., 2005; Reverte et al., 2006; Toyoshima and Nishida, 2007; Toyoshima et al., 2007; Taddei et al., 2008). Surprisingly, we saw no effect of $\beta 1$-integrin blocking on mitotic spindle orientation in RPCs. Our data suggest that RPC mitotic spindle orientation is $\beta 1$-integrin-independent and relies on DG instead. To our knowledge, ours is the first report of DG having an effect on mitotic spindle positioning. Furthermore, the phenotypes observed in Lamb2 $2^{-1-}$ retinas, such as ILM disruption, rosette formation in the ONL, and diminished RPC proliferation, are phenocopied in a model where DG was depleted from the developing Xenopus retina (Lunardi et al., 2006), reinforcing DG's role in retinal development. These findings are of wide reaching importance not only in the field of developmental biology, but in cell biology as well, opening a new avenue of studies.

However, in the developing Xenopus retina, $\beta 1$-integrin blocking phenocopies some of the DG disruption phenotypes, suggesting an overlap in the signaling cascades between the two receptors. This overlap becomes apparent in our $\mathrm{Lamb2}^{-/}$retinal explants. Blocking both DG and $\beta 1$-integrin in Lamb2 ${ }^{-1-}$ explants following rescue with laminin 521 appears to be additive and results in near stochastic orientation of the mitotic spindles. This synergistic effect is not observed when both receptor pathways are blocked in WT retinas, suggesting a change in the dependence on $\beta 1$-integrin in the absence of Lamb2. While $\beta 1$ integrin signaling alone does not appear to affect RPC mitotic spindle orientation, it does affect proliferation, possibly via mediating cell-cycle dynamics or other mechanisms. Compensation by other integrins cannot be excluded at this point and remains a possibility. Further investigation of the role of laminin-integrin and laminin-DG signaling in RPCs is required.

\section{BM contact modulates proliferative capacity in multipotent progenitors of the CNS}

As the retina is part of the CNS, it perhaps is not surprising that RPCs display similar behavior to their cortical counterparts, the RG. Both have radial processes contacting the BM, undergo interkinetic nuclear migration as they progress through the cell cycle, and divide at the apical surface (Sauer, 1935, 1936; Takahashi et al., 1993; Baye and Link, 2007, 2008). As in RPCs, RG division direction is predominantly symmetric (Smart, 1972;
Chenn and McConnell, 1995; Heins et al., 2001; Estivill-Torrus et al., 2002; Haydar et al., 2003; Kosodo et al., 2004; Fish et al., 2006; Stricker et al., 2006; Konno et al., 2008). Dividing RG are capable of producing more RG, differentiating neurons, as well as restricted, IPCs (Huttner and Kosodo, 2005; for review, see Götz and Huttner, 2005). While RG have the potential to self-renew, IPCs generally divide only once to produce two neurons (Haubensak et al., 2004; Miyata et al., 2004; Noctor et al., 2004, 2008; Wu et al., 2005; Attardo et al., 2008). Unlike in RG, IPC cytokinesis occurs at nearly random orientation (Attardo et al., 2008). The key observation is that the retention of the basal fiber and contact with the BM are important for preserving the RG identity. RG remain highly polarized while in contact with the BM, whereas IPCs lack such contacts, leading to speculation that the loss of apicobasal polarity leads to the restriction in their proliferative capacity (Noctor et al., 2004; Attardo et al., 2008).

Our current findings suggest that laminins in the BM provide essential signaling cues that are especially important in the context of 3D tissue structure and morphogenesis. Indeed, it has already been demonstrated that polarity in Müller glia, the final product of RPC division, is regulated by laminins (Hirrlinger et al., 2011). BM contact dictates progenitor behavior and tissue development by providing environmental cues that convey proper mitotic orientation and proliferative capacity. Deletion of Lamb2 leads to decreased proliferation and an increased incidence of mitotic RPCs lacking BPs. These cells display a nearly stochastic mitotic spindle positioning, similar to what is observed in the cortical IPCs lacking BM contact. As this study focused specifically on RPCs in mitosis, it is currently unknown whether laminins affect BP stability in other stages of cell cycle as well. BP disruption during interphase would necessarily affect interkinetic nuclear migration, which would likely result in ectopic mitoses throughout the retina. Ectopic mitoses were not observed; we thus hypothesize that the loss of polarity cue provided by the $\mathrm{BP}$ attachment to the ILM specifically affects the spindle apparatus orientation during mitosis. Further experiments to link the BP to the spindle apparatus are warranted.

Disruption of DG-laminin signaling at the BM also results in a nearly stochastic mitotic axis orientation and limits proliferation, suggesting that BM-cell signaling is DG-mediated. We propose that the loss of contact with the BM is the crucial step in the transition from a multipotent progenitor to a restricted transient amplifier during development. Further investigation of the BMcell contact dynamics, and the role of laminins and DG therein, will be necessary to shed more light on its impact on development and morphogenesis.

\section{References}

Agathocleous M, Harris WA (2009) From progenitors to differentiated cells in the vertebrate retina. Annu Rev Cell Dev Biol 25:45-69. CrossRef Medline

Aszodi A, Hunziker EB, Brakebusch C, Fässler R (2003) Betal integrins regulate chondrocyte rotation, G1 progression, and cytokinesis. Genes Dev 17:2465-2479. CrossRef Medline

Attardo A, Calegari F, Haubensak W, Wilsch-Bräuninger M, Huttner WB (2008) Live imaging at the onset of cortical neurogenesis reveals differential appearance of the neuronal phenotype in apical versus basal progenitor progeny. PLoS One 3:e2388. CrossRef Medline

Baena-López LA, Baonza A, García-Bellido A (2005) The orientation of cell divisions determines the shape of Drosophila organs. Curr Biol 15:16401644. CrossRef Medline

Baye LM, Link BA (2007) Interkinetic nuclear migration and the selection of neurogenic cell divisions during vertebrate retinogenesis. J Neurosci 27: 10143-10152. CrossRef Medline 
Baye LM, Link BA (2008) Nuclear migration during retinal development. Brain Res 1192:29-36. CrossRef Medline

Carter-Dawson LD, LaVail MM (1979) Rods and cones in the mouse retina: I. structural analysis using light and electron microscopy. J Comp Neurol 188:245-262. CrossRef Medline

Cepko CL, Austin CP, Yang X, Alexiades M, Ezzeddine D (1996) Cell fate determination in the vertebrate retina. Proc Natl Acad Sci U S A 93:589595. CrossRef Medline

Chenn A, McConnell SK (1995) Cleavage orientation and the asymmetric inheritance of Notch1 immunoreactivity in mammalian neurogenesis. Cell 82:631-641. CrossRef Medline

Chou YH, Khuon S, Herrmann H, Goldman RD (2003) Nestin promotes the phosphorylation-dependent disassembly of vimentin intermediate filaments during mitosis. Mol Biol Cell 14:1468-1478. CrossRef Medline

Clements R, Turk R, Campbell KP, Wright KM (2017) Dystroglycan maintains inner limiting membrane integrity to coordinate retinal development. J Neurosci 37:8559-8574. CrossRef Medline

Condic ML, Letourneau PC (1997) Ligand-induced changes in integrin expression regulate neuronal adhesion and neurite outgrowth. Nature 389: 852-856. CrossRef Medline

Dénes V, Witkovsky P, Koch M, Hunter DD, Pinzón-Duarte G, Brunken WJ (2007) Laminin deficits induce alterations in the development of dopaminergic neurons in the mouse retina. Vis Neurosci 24:549-562. CrossRef Medline

Eiraku M, Takata N, Ishibashi H, Kawada M, Sakakura E, Okuda S, Sekiguchi K, Adachi T, Sasai Y (2011) Self-organizing optic-cup morphogenesis in three-dimensional culture. Nature 472:51-56. CrossRef Medline

Ervasti JM, Campbell KP (1991) Membrane organization of the dystrophinglycoprotein complex. Cell 66:1121-1131. CrossRef Medline

Ervasti JM, Ohlendieck K, Kahl SD, Gaver MG, Campbell KP (1990) Deficiency of a glycoprotein component of the dystrophin complex in dystrophic muscle. Nature 345:315-319. CrossRef Medline

Estivill-Torrus G, Pearson H, van Heyningen V, Price DJ, Rashbass P (2002) Pax6 is required to regulate the cell cycle and the rate of progression from symmetrical to asymmetrical division in mammalian cortical progenitors. Development 129:455-466. Medline

Fish JL, Kosodo Y, Enard W, Pääbo S, Huttner WB (2006) Aspm specifically maintains symmetric proliferative divisions of neuroepithelial cells. Proc Natl Acad Sci U S A 103:10438-10443. CrossRef Medline

Gillies TE, Cabernard C (2011) Cell division orientation in animals. Curr Biol 21:R599-R609. CrossRef Medline

Götz M, Huttner WB (2005) The cell biology of neurogenesis. Nat Rev Mol Cell Biol 6:777-788. CrossRef Medline

Griffith LG, Swartz MA (2006) Capturing complex 3D tissue physiology in vitro. Nat Rev Mol Cell Biol 7:211-224. CrossRef Medline

Hafler BP, Surzenko N, Beier KT, Punzo C, Trimarchi JM, Kong JH, Cepko CL (2012) Transcription factor Olig2 defines subpopulations of retinal progenitor cells biased toward specific cell fates. Proc Natl Acad Sci U S A 109:7882-7887. CrossRef Medline

Haubensak W, Attardo A, Denk W, Huttner WB (2004) Neurons arise in the basal neuroepithelium of the early mammalian telencephalon: a major site of neurogenesis. Proc Natl Acad Sci U S A 101:3196-3201. CrossRef Medline

Haydar TF, Ang E Jr, Rakic P (2003) Mitotic spindle rotation and mode of cell division in the developing telencephalon. Proc Natl Acad Sci U S A 100:2890-2895. CrossRef Medline

Heins N, Cremisi F, Malatesta P, Gangemi RM, Corte G, Price J, Goudreau G, Gruss P, Götz M (2001) Emx2 promotes symmetric cell divisions and a multipotential fate in precursors from the cerebral cortex. Mol Cell Neurosci 18:485-502. CrossRef Medline

Hirrlinger PG, Pannicke T, Winkler U, Claudepierre T, Varshney S, Schulze C, Reichenbach A, Brunken WJ, Hirrlinger J (2011) Genetic deletion of laminin isoforms $\beta 2$ and $\gamma 3$ induces a reduction in Kir4.1 and aquaporin-4 expression and function in the retina. PLoS One 6:e16106. CrossRef Medline

Holt CE, Bertsch TW, Ellis HM, Harris WA (1988) Cellular determination in the Xenopus retina is independent of lineage and birth date. Neuron 1:15-26. CrossRef Medline

Huttner WB, Kosodo Y (2005) Symmetric versus asymmetric cell division during neurogenesis in the developing vertebrate central nervous system. Curr Opin Cell Biol 17:648-657. CrossRef Medline

Klein G, Langegger M, Timpl R, Ekblom P (1988) Role of laminin A chain in the development of epithelial cell polarity. Cell 55:331-341. CrossRef Medline

Konno D, Shioi G, Shitamukai A, Mori A, Kiyonari H, Miyata T, Matsuzaki F (2008) Neuroepithelial progenitors undergo LGN-dependent planar divisions to maintain self-renewability during mammalian neurogenesis. Nat Cell Biol 10:93-101. CrossRef Medline

Kosodo Y, Röper K, Haubensak W, Marzesco AM, Corbeil D, Huttner WB (2004) Asymmetric distribution of the apical plasma membrane during neurogenic divisions of mammalian neuroepithelial cells. EMBO J 23: 2314-2324. CrossRef Medline

Lechler T, Fuchs E (2005) Asymmetric cell divisions promote stratification and differentiation of mammalian skin. Nature 437:275-280. CrossRef Medline

Li M, Sakaguchi DS (2004) Inhibition of integrin-mediated adhesion and signaling disrupts retinal development. Dev Biol 275:202-214. CrossRef Medline

Libby RT, Lavallee CR, Balkema GW, Brunken WJ, Hunter DD (1999) Disruption of laminin beta 2 chain production causes alterations in morphology and function in the CNS. J Neurosci 19:9399-9411. CrossRef Medline

Lunardi A, Cremisi F, Dente L (2006) Dystroglycan is required for proper retinal layering. Dev Biol 290:411-420. CrossRef Medline

Manninen A (2015) Epithelial polarity-generating and integrating signals from the ECM with integrins. Exp Cell Res 334:337-349. CrossRef Medline

McConnell SK (1995) Constructing the cerebral cortex: neurogenesis and fate determination. Neuron 15:761-768. CrossRef Medline

Miner JH, Li C, Mudd JL, Go G, Sutherland AE (2004) Compositional and structural requirements for laminin and basement membranes during mouse embryo implantation and gastrulation. Development 131:22472256. CrossRef Medline

Miyata T, Kawaguchi A, Saito K, Kawano M, Muto T, Ogawa M (2004) Asymmetric production of surface-dividing and non-surface-dividing cortical progenitor cells. Development 131:3133-3145. CrossRef Medline

Nikonov SS, Brown BM, Davis JA, Zuniga FI, Bragin A, Pugh EN Jr, Craft CM (2008) Mouse cones require an arrestin for normal inactivation of phototransduction. Neuron 59:462-474. CrossRef Medline

Noakes PG, Gautam M, Mudd J, Sanes JR, Merlie JP (1995) Aberrant differentiation of neuromuscular junctions in mice lacking s-laminin/ laminin beta 2. Nature 374:258-262. CrossRef Medline

Noctor SC, Martínez-Cerdeño V, Ivic L, Kriegstein AR (2004) Cortical neurons arise in symmetric and asymmetric division zones and migrate through specific phases. Nat Neurosci 7:136-144. CrossRef Medline

Noctor SC, Martínez-Cerdeño V, Kriegstein AR (2008) Distinct behaviors of neural stem and progenitor cells underlie cortical neurogenesis. J Comp Neurol 508:28-44. CrossRef Medline

O’Brien LE, Jou TS, Pollack AL, Zhang Q, Hansen SH, Yurchenco P, Mostov KE (2001) Racl orientates epithelial apical polarity through effects on basolateral laminin assembly. Nat Cell Biol 3:831-838. CrossRef Medline

Pinzón-Duarte G, Kohler K, Arango-González B, Guenther E (2000) Cell differentiation, synaptogenesis, and influence of the retinal pigment epithelium in a rat neonatal organotypic retina culture. Vision Res 40:34553465. CrossRef Medline

Pinzón-Duarte G, Daly G, Li YN, Koch M, Brunken WJ (2010) Defective formation of the inner limiting membrane in laminin $\beta 2$ - and $\gamma 3$-null mice produces retinal dysplasia. Invest Ophthalmol Vis Sci 51:1773-1782. CrossRef Medline

Reverte CG, Benware A, Jones CW, LaFlamme SE (2006) Perturbing integrin function inhibits microtubule growth from centrosomes, spindle assembly, and cytokinesis. J Cell Biol 174:491-497. CrossRef Medline

Rowan S, Cepko CL (2004) Genetic analysis of the homeodomain transcription factor Chx10 in the retina using a novel multifunctional BAC transgenic mouse reporter. Dev Biol 271:388-402. CrossRef Medline

Sauer FC (1935) Mitosis in the neural tube. J Comp Neurol 62:377-405. CrossRef

Sauer FC (1936) The interkinetic migration of embryonic epithelial nuclei. J Morphol 60:1-11. CrossRef

Segalen M, Bellaïche Y (2009) Cell division orientation and planar cell polarity pathways. Semin Cell Dev Biol 20:972-977. CrossRef Medline

Smart IH (1972) Proliferative characteristics of the ependymal layer during the early development of the mouse diencephalon, as revealed by recording the number, location, and plane of cleavage of mitotic figures. J Anat 113:109-129. Medline 
Smyth N, Vatansever HS, Murray P, Meyer M, Frie C, Paulsson M, Edgar D (1999) Absence of basement membranes after targeting the LAMC1 gene results in embryonic lethality due to failure of endoderm differentiation. J Cell Biol 144:151-160. CrossRef Medline

Stoppini L, Buchs PA, Muller D (1991) A simple method for organotypic cultures of nervous tissue. J Neurosci Methods 37:173-182. CrossRef Medline

Stricker SH, Meiri K, Götz M (2006) P-GAP-43 is enriched in horizontal cell divisions throughout rat cortical development. Cereb Cortex 16:1121i131. CrossRef Medline

Taddei I, Deugnier MA, Faraldo MM, Petit V, Bouvard D, Medina D, Fässler R, Thiery JP, Glukhova MA (2008) Betal integrin deletion from the basal compartment of the mammary epithelium affects stem cells. Nat Cell Biol 10:716-722. CrossRef Medline

Takahashi T, Nowakowski RS, Caviness VS Jr (1993) Cell cycle parameters and patterns of nuclear movement in the neocortical proliferative zone of the fetal mouse. J Neurosci 13:820-833. CrossRef Medline

Théry M, Racine V, Pépin A, Piel M, Chen Y, Sibarita JB, Bornens M (2005) The extracellular matrix guides the orientation of the cell division axis. Nat Cell Biol 7:947-953. CrossRef Medline

Toyoshima F, Nishida E (2007) Integrin-mediated adhesion orients the spindle parallel to the substratum in an EB1- and myosin X-dependent manner. EMBO J 26:1487-1498. CrossRef Medline

Toyoshima F, Matsumura S, Morimoto H, Mitsushima M, Nishida E (2007) PtdIns $(3,4,5) \mathrm{P} 3$ regulates spindle orientation in adherent cells. Dev Cell 13:796-811. CrossRef Medline

Turner DL, Cepko CL (1987) A common progenitor for neurons and glia persists in rat retina late in development. Nature 328:131-136. CrossRef Medline

Turner DL, Snyder EY, Cepko CL (1990) Lineage-independent determina- tion of cell type in the embryonic mouse retina. Neuron 4:833-845. CrossRef Medline

Varshney S, Hunter DD, Brunken WJ (2015) Extracellular matrix components regulate cellular polarity and tissue structure in the developing and mature retina. J Ophthalmic Vis Res 10:329-339. CrossRef Medline

Wang AZ, Ojakian GK, Nelson WJ (1990) Steps in the morphogenesis of a polarized epithelium: II. Disassembly and assembly of plasma membrane domains during reversal of epithelial cell polarity in multicellular epithelial (MDCK) cysts. J Cell Sci 95:153-165. Medline

Wu SX, Goebbels S, Nakamura K, Nakamura K, Kometani K, Minato N, Kaneko T, Nave KA, Tamamaki N (2005) Pyramidal neurons of upper cortical layers generated by NEX-positive progenitor cells in the subventricular zone. Proc Natl Acad Sci U S A 102:17172-17177. CrossRef Medline

Xu R, Boudreau A, Bissell MJ (2009) Tissue architecture and function: dynamic reciprocity via extra- and intra-cellular matrices. Cancer Metastasis Rev 28:167-176. CrossRef Medline

Yao Y (2017) Laminin: loss-of-function studies. Cell Mol Life Sci 74:10951115. CrossRef Medline

Yingling J, Youn YH, Darling D, Toyo-Oka K, Pramparo T, Hirotsune S, Wynshaw-Boris A (2008) Neuroepithelial stem cell proliferation requires LIS1 for precise spindle orientation and symmetric division. Cell 132:474-486. CrossRef Medline

Young RW (1985) Cell differentiation in the retina of the mouse. Anat Rec 212:199-205. CrossRef Medline

Yurchenco PD (2011) Basement membranes: cell scaffoldings and signaling platforms. Cold Spring Harb Perspect Biol 3:a004911. CrossRef Medline

Zieve GW, Heidemann SR, McIntosh JR (1980) Isolation and partial characterization of a cage of filaments that surrounds the mammalian mitotic spindle. J Cell Biol 87:160-169. CrossRef Medline 